\title{
The molecular genetic make-up of male breast cancer
}

\author{
Cathy B Moelans' ${ }^{1}$ Joep de Ligt ${ }^{2}$, Petra van der Groep ${ }^{1,3}$, Pjotr Prins², Nicolle J M Besselink ${ }^{2,4}$, Marlous Hoogstraat ${ }^{2}$, \\ Natalie D ter Hoeve1, Miangela M Lacle1, Robert Kornegoor5, Carmen C van der Pol6, Wendy W J de Leng1, \\ Ellis Barbé7, Bert van der Vegt ${ }^{8}$, John Martens ${ }^{9}$, Peter Bult ${ }^{10}$, Vincent T H B M Smit'11, Marco J Koudijs ${ }^{2,4}$, \\ Isaac J Nijman2,4, Emile E Voest4,12, Pier Selenica13, Britta Weigelt13, Jorge S Reis-Filho13, Elsken van der Wall6, \\ Edwin Cuppen ${ }^{2,14}$ and Paul J van Diest ${ }^{1}$
}

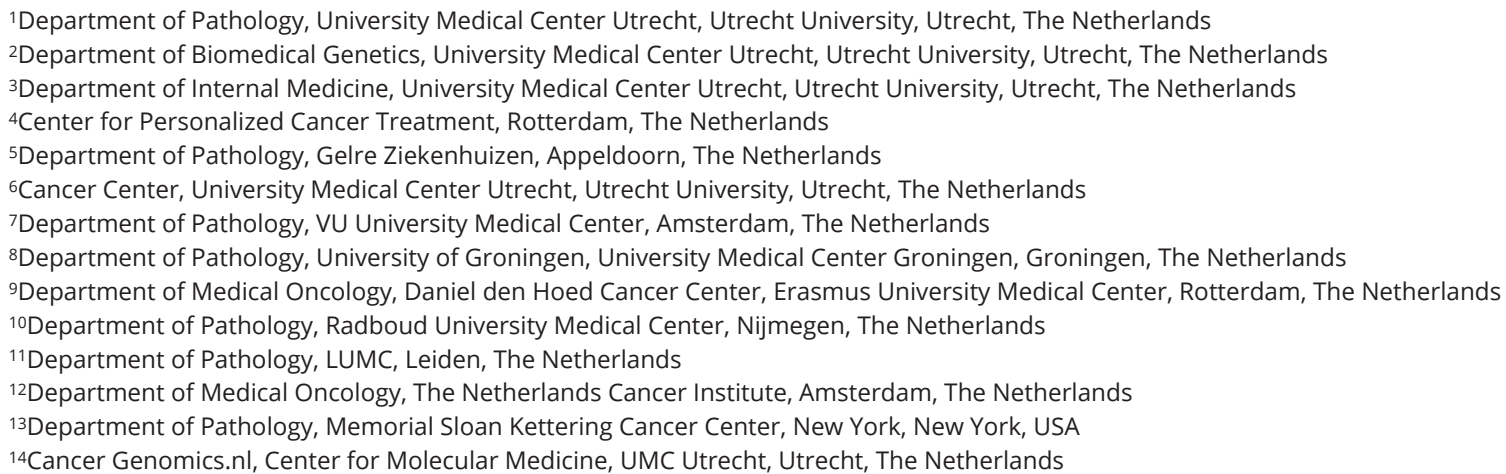

Correspondence should be addressed to C B Moelans: C.B.Moelans@umcutrecht.nl

\begin{abstract}
Male breast cancer (MBC) is extremely rare and accounts for less than $1 \%$ of all breast malignancies. Therefore, clinical management of MBC is currently guided by research on the disease in females. In this study, DNA obtained from 45 formalin-fixed paraffin-embedded (FFPE) MBCs with and 90 MBCs (52 FFPE and 38 fresh-frozen) without matched normal tissues was subjected to massively parallel sequencing targeting all exons of 1943 cancerrelated genes. The landscape of mutations and copy number alterations was compared to that of publicly available estrogen receptor (ER)-positive female breast cancers (smFBCs) and correlated to prognosis. From the $135 \mathrm{MBCs}, 90 \%$ showed ductal histology, 96\% were ER-positive, 66\% were progesterone receptor (PR)-positive, and 2\% HER2-positive, resulting in 50, 46 and $4 \%$ luminal A-like, luminal B-like and basal-like cases, respectively. Five patients had Klinefelter syndrome (4\%) and $11 \%$ of patients harbored pathogenic BRCA2 germline mutations. The genomic landscape of MBC to some extent recapitulated that of smFBC, with recurrent PIK3CA (36\%) and GATA3 (15\%) somatic mutations, and with $40 \%$ of the most frequently amplified genes overlapping between both sexes. TP53 (3\%) somatic mutations were significantly less frequent in $\mathrm{MBC}$ compared to $\mathrm{smFBC}$, whereas somatic mutations in genes regulating chromatin function and homologous recombination deficiency-related signatures were more prevalent. MDM2 amplifications were frequent (13\%), correlated with protein overexpression ( $P=0.001)$ and predicted poor outcome $(P=0.007)$. In conclusion, despite similarities in the genomic landscape between MBC and SmFBC, MBC is a molecularly unique and heterogeneous disease requiring its own clinical trials and treatment guidelines.
\end{abstract}

Endocrine-Related Cancer (2019) 26, 779-794 (c) 2019 Society for Endocrinology Published by Bioscientifica Ltd. Printed in Great Britain
Key Words
- breast cancer
- male
- mutation
- copy number
- amplification
- genomic 


\section{Introduction}

Male breast cancer (MBC) is a rare disease accounting for about $1 \%$ of all breast cancers (Jemal et al. 2010, Giordano 2018). Five-year overall survival is lower compared to female patients, related to the older age at diagnosis and more advanced stage at presentation (Giordano et al. 2004, Stang \& Thomssen 2008). Major genetic factors associated with an increased risk of $\mathrm{MBC}$ include $B R C A 2$ and BRCA1 germline mutations, Klinefelter syndrome (KS) and family history. Additional suspected genetic factors include CHEK2 and PALB2 mutations, with less supporting evidence for $A R$ and FANCM gene mutations, CYP17 polymorphism and Cowden syndrome (Weiss et al. 2005, Silvestri et al. 2017, 2018). Epidemiologic risk factors include hormonal imbalance and radiation exposure (Thomas et al. 1994, Abdelwahab Yousef 2017). The majority of MBCs are invasive ductal carcinomas with high estrogen (ER) and progesterone (PR) receptor levels without overexpression of HER2 (Kornegoor et al. 2012c).

Because of its low incidence, $\mathrm{MBC}$ has not been studied as extensively as female breast cancer (FBC). Few retrospective studies have included more than 100 cases. Therefore, despite possible differences in pathogenesis, biology and genetics between both sexes, treatment strategies for $\mathrm{MBC}$ have largely been extrapolated from FBC. This, in combination with the older age at diagnosis, hampers improvement in outcome as has been seen in FBC over the last decades.

Recent large-scale cross-platform projects have provided a detailed characterization of the genomic landscape of FBC (Cancer Genome Atlas Network 2012, Curtis et al. 2012, Nik-Zainal et al. 2016, Pereira et al. 2016, Bailey et al. 2018, Berger et al. 2018). The Cancer Genome Atlas (TCGA) (Cancer Genome Atlas Network 2012) reported the enrichment of specific mutations in PIK3CA (47\%), GATA3 (14\%), MAP3K1 (13\%), TP53 (12\%), CDH1 (10\%) and MAP2K4 (7\%) with the luminal A subtype and in TP53 (31\%), PIK3CA (32\%) and MAP3K1 (5\%) within the luminal B subtype (Gao et al. 2015). Integrated genomic/transcriptomic analysis of breast cancers from METABRIC (Molecular Taxonomy of Breast Cancer International Consortium) identified 40 putative mutation driver genes (Curtis et al. 2012, Pereira et al. 2016). Subsequent studies identified overlapping as well as new probable driver mutations (Nik-Zainal et al. 2016, Bailey et al. 2018, Berger et al. 2018).

Genomic data on MBC are scarce. On a molecular level, like $\mathrm{FBC}, \mathrm{MBC}$ is a heterogeneous disease with differences in transcriptional (Callari et al. 2011, Johansson et al. 2012), copy number (Johansson et al. 2011, Tommasi et al. 2011, Biesma et al. 2015, Piscuoglio et al. 2016), microRNA (Fassan et al. 2009, Lehmann et al. 2010) and methylation (Kornegoor et al. 2012a, Johansson et al. 2015, Rizzolo et al. 2018) patterns. Genomic gains appear to be more common in $\mathrm{MBC}$ than in $\mathrm{FBC}$ and often involve whole chromosome arms, while genomic losses and high-level amplifications are less frequent (Johansson et al. 2011, Tommasi et al. 2011, Kornegoor et al. 2012b, Lacle et al. 2013, 2015, Biesma et al. 2015). Luminal A-like and luminal B-like MBC subtypes seem to exhibit remarkably similar copy number aberration profiles, in contrast to their distinct landscape of somatic mutations (Piscuoglio et al. 2016). Piscuoglio et al. recently studied mutations of 59 MBCs by massively parallel sequencing the exons of 241 genes and demonstrated that MBCs less frequently harbored PIK3CA (20\%) and TP53 mutations (8.5\%) than subtype-matched (sm)FBC (Piscuoglio et al. 2016). The most frequently mutated genes in luminal A-like MBC included PIK3CA and MAP3K1 (both at 12\%), whereas the most frequently mutated genes in luminal B-like $\mathrm{MBC}$ were PIK3CA (24\%) and GATA3 (21\%).

Thus, MBCs share many features with FBCs, but there is evidence for distinct differences with potential implications for clinical management. Here we (i) used targeted capture massively parallel sequencing of 1943 cancer-related genes to study the mutational and copy number landscape in a cohort of $135 \mathrm{MBCs}$, including 5 patients with KS and (ii) compared these profiles to those of smFBCs.

\section{Materials and methods}

\section{Patients and samples}

MBC samples were collected from ten pathology laboratories throughout The Netherlands. Patients were diagnosed between 1986 and 2011. Pathology reports were used to extract age, tumor size and lymph node status. Tumor slides were reviewed by three expert breast pathologists (PJvD, RK, MML) to confirm diagnosis and demarcate normal and tumor areas. Histological type (WHO) and grade were assessed as described previously (Elston \& Ellis 1991, Van Diest et al. 1992). Patient and tumor characteristics are summarized in Table 1. All samples and databases were anonymized before use. The Dutch national ethical guidelines (www.federa.org) state that no ethical approval is required for the use of anonymous leftover tissue, and this is also part of the standard treatment agreement (Van Diest 2002). 
Table 1 Clinico-pathologic features and immunohistochemical subtypes of the 135 male breast cancers included in this study.

\begin{tabular}{|c|c|c|c|}
\hline Clinico-pathologic features & $n=135$ & $\%$ & Actual \% \\
\hline Median age at diagnosis & \multicolumn{2}{|l|}{67 (range 32-89) } & \\
\hline Median mitotic activity index & \multicolumn{2}{|l|}{10 (range 0-56) } & \\
\hline Median tumor size $(\mathrm{cm})$ & \multicolumn{2}{|c|}{2.3 (range 0.8-11) } & \\
\hline \multicolumn{4}{|l|}{ Type } \\
\hline Ductal & 121 & 89.6 & 90.3 \\
\hline Lobular & 2 & 1.5 & 1.5 \\
\hline Other & 11 & 8.1 & 8.2 \\
\hline Missing & 1 & 0.7 & \\
\hline \multicolumn{4}{|l|}{ Histologic gradea } \\
\hline 1 & 27 & 20.0 & 22.7 \\
\hline 2 & 49 & 36.3 & 41.2 \\
\hline 3 & 43 & 31.9 & 36.1 \\
\hline Missing & 16 & 11.9 & \\
\hline \multicolumn{4}{|l|}{ Mitotic activity index/2 mm² } \\
\hline$<8$ mitoses & 50 & 37.0 & 40.7 \\
\hline 8-14 mitoses & 35 & 25.9 & 28.5 \\
\hline$>14$ mitoses & 38 & 28.1 & 30.9 \\
\hline Missing & 12 & 8.9 & \\
\hline \multicolumn{4}{|l|}{ ER status } \\
\hline Negative & 6 & 4.4 & 4.5 \\
\hline Positive & 128 & 94.8 & 95.5 \\
\hline Missing & 1 & 0.7 & \\
\hline \multicolumn{4}{|l|}{ PR status } \\
\hline Negative & 45 & 33.3 & 33.8 \\
\hline Positive & 88 & 65.2 & 66.2 \\
\hline Missing & 2 & 1.5 & \\
\hline \multicolumn{4}{|l|}{ HER2 status } \\
\hline Negative & 129 & 95.6 & 97.7 \\
\hline Positive & 3 & 2.2 & 2.3 \\
\hline Missing & 3 & 2.2 & \\
\hline \multicolumn{4}{|l|}{ LN status } \\
\hline Negative & 48 & 35.6 & 41.4 \\
\hline Positive & 68 & 50.4 & 58.6 \\
\hline Missing & 19 & 14.1 & \\
\hline \multicolumn{4}{|l|}{ Ki-67 labeling index } \\
\hline $\operatorname{Low}(<14 \%)$ & 94 & 69.6 & 71.8 \\
\hline High $(\geq 14 \%)$ & 37 & 27.4 & 28.2 \\
\hline Missing & 4 & 3.0 & \\
\hline \multicolumn{4}{|l|}{ Surrogate intrinsic subtype } \\
\hline Luminal A-like & 66 & 48.9 & 50.4 \\
\hline Luminal B-like & 60 & 44.4 & 45.8 \\
\hline HER2-driven & 0 & 0.0 & 0.0 \\
\hline Basal-like & 5 & 3.7 & 3.8 \\
\hline Missing & 4 & 3.0 & \\
\hline
\end{tabular}

aAccording to the Nottingham grading system (Elston \& Ellis 1991); bdefined by immunohistochemistry according to St. Gallen criteria (Goldhirsch et al. 2013).

ER, estrogen receptor; HER2, human epidermal growth factor receptor 2; $L N$, lymph node; PR, progesterone receptor.

Immunohistochemistry was repeated to classify MBCs into the four different intrinsic subtypes according to the St. Gallen International criteria for FBC (Goldhirsch et al. 2013). Luminal A-like tumors were defined as ER-positive (1\%) and PR-positive ( $\geq 20 \%$ positive cells), HER2-negative

(c) 2019 Society for Endocrinology Published by Bioscientifica Ltd. Printed in Great Britain and $\mathrm{Ki} 67$ low ( $<14 \%$ positive cells), whereas the remaining ER-positive tumors were classified as luminal B-like. HER2-driven tumors were defined as ER/PR negative and HER2 overexpressed or amplified (ASCO/CAP guidelines; Wolff et al. 2013), and basal-like tumors as ER/PR/HER2 negative. The DNA extraction procedure is detailed in Supplementary methods (see section on supplementary data given at the end of this article). All tumor samples consisted of $60 \%$ or more neoplastic cells, as assessed by pathology review.

\section{Targeted capture massively parallel sequencing}

Sequencing libraries were prepared from $600 \mathrm{ng}$ of sheared DNA as previously described with a few modifications (Harakalova et al. 2011). After end repair samples were A-tailed, followed by T-tailed adaptor ligation. Samples were pooled and subjected to hybrid capture enrichment using a custom SureSelect assay (Agilent) containing baits targeting all exons of 1943 genes including known oncogenes, tumor suppressor genes, all kinases and genes involved in important pathways related to tumorigenesis and anti-cancer treatment (e.g., angiogenesis; apoptosis; and EGFR, PIK3CA, TGF $\beta$, mTOR and VEGF pathways were included) (Supplementary Table 1). Pre-barcoded individual libraries were pooled, enriched and subsequently sequenced on the SOLiD 5500 system (Thermo Fisher). Supplementary Table 2 summarizes sequencing statistics. All sequencing data have been deposited in EGA under accession number EGAS00001002683.

SOLiD data were processed with our in-house developed pipeline v1.2.1 (https://github.com/ UMCUGenetics/IAP) by Genome Analysis Toolkit (GATK) v3.2.2 calling for all samples according to best practices guidelines, including somatic mutation analysis for matched pairs (Mckenna et al. 2010, Van der Auwera et al. 2013). Filtering was applied to select high quality variants (coverage $\geq 10$, allele fraction $\geq 0.15$ ) and to exclude germline variants (population frequency $<5 \%$ ), full details available in Supplementary methods.

Copy number alteration (CNA) analysis was performed using Codecz v1.0.1 with the appropriate design file kinome_design_SS_V2_110811. For FFPE samples all (normal) controls were merged into a control pool against which the tumors were analyzed. For FF samples, each sample was compared to the complete FF tumor data set as a means of normalization. Z-scores were calculated as described by Hoogstraat et al. (2015).

Mutational signature analysis was performed on MBCs with available ER and HER2 status $(n=129)$ and 
matched 1:2 with FBCs from TCGA with the same receptor status $(n=258)$. Mutational signatures were defined by deconstructSigs using all SNVs for samples with $\geq 20$ somatic SNVs, as previously described (Rosenthal et al. 2016, Mueller et al. 2018).

In addition, targeted next-generation sequencing (NGS) of the complete coding sequences of BRCA1 and $B R C A 2$ was performed on normal tissue (germline) using the Oncomine BRCA FFPE gene panel (ThermoFisher) according to the manufacturer's instructions. In short, 20 ng FFPE DNA was used for library preparation with 24 PCR cycles. Emulsion PCR and enrichment were performed using the Ion PGM Template OT2 200 Template Kit and the Ion One Touch 2 instrument (ThermoFisher). Sequencing was performed using the Ion PGM Sequencing 200 kit v2 using the Ion 318 chip (ThermoFisher). Samples were run on the Ion Torrent PGM System (ThermoFisher). Sequencing data were analyzed using SeqNext (JSI medical systems).

\section{Sanger sequencing}

A selection of NGS variants was validated by Sanger sequencing. After Exonuclease I - Shrimp Alkaline Phosphatase enzymatic cleanup of amplified PCR products, BigDye Terminator v1.1 Cycle Sequencing (ThermoFisher) of $1 \mu \mathrm{L}$ PCR product and Sephadex G-50 based sequencing reaction cleanup, sequencing products were analyzed on a 3730 DNA Analyzer (ThermoFisher). Primers are listed in Supplementary Table 3. Sanger sequencing validation is described in the Supplementary results section.

\section{MDM2 immunohistochemistry}

Tissue microarray (triplicate cores) or full $4 \mu \mathrm{m}$ slides were deparaffinized, pretreated for $24 \mathrm{~min}$ in CC1 (EDTA pH8.0) and stained on a Ventana Benchmark XT autostainer using a mouse monoclonal anti-MDM2 antibody (ThermoFisher Scientific, clone IF2, dilution 1/25). All samples with sufficient tumor material $(n=106)$ were scored as positive (nuclear staining in at least $5 \%$ positive tumor cells) or negative by consensus of two observers.

\section{Statistics}

Associations between gene copy number or mutation status and clinicopathological features were calculated using the Pearson chi-square test (or Fisher's exact test when appropriate) for categorical variables

(c) 2019 Society for Endocrinology Published by Bioscientifica Ltd. Printed in Great Britain
(IBM SPSS Statistics, version 21). Associations were evaluated for all genes and only significant associations were reported. Mitotic activity index (MAI) was dichotomized as $\leq 14$ or $>14$ mitoses $/ 2 \mathrm{~mm}^{2}$, tumor size as $\leq 2$ or $>2 \mathrm{~cm}$, age as $\leq 60$ or $>60$ and histological grade as grade $1 / 2$ versus grade 3 (Elston \& Ellis 1991). Mutation load and CNA load were dichotomized at the median (7 and 62 , respectively). Associations of mutational load with clinicopathological characteristics are described in the Supplementary results section. Cluster analysis for CNAs was performed in R using hclust (default) and heatmap.2. Five-year overall survival (OS) was analyzed with Kaplan-Meier plots/log-rank test. Backward LR Cox proportional hazards models were used to estimate risk of death adjusted for parameters significant or with trend in univariate analyses. Hazard ratios (HRs) were calculated with 95\% confidence intervals (CIs). For multivariable analysis, $P$ values $>0.1$ were removed from the model. MedCalc statistical software was used for comparison of SNV and CNA proportions to publicly available METABRIC and $\mathrm{MBC}$ data. Corrections for multiple comparisons were applied according to Holm-Bonferroni. For pathway analysis, PANTHER, version 11.1 was used (released 2016-10-24) (Mi et al. 2017).

\section{Results}

\section{Characteristics of the cohort}

From the 135 MBCs, 90\% showed ductal histology, 96\% were ER positive, $66 \%$ were PR positive and 2\% HER2 positive, resulting in 50, 46 and $4 \%$ luminal A-like, luminal B-like and basal-like cases, respectively. None of the cases was HER2 driven (Table 1). Five patients had KS (4\%) and 11\% (5/44 with paired normal tissue) of patients harbored pathogenic BRCA2 germline mutations. The median age at diagnosis was 67 years. Follow-up was available for 111/135 patients. Median follow-up was 52 months (range 1-243), and 59 patients were alive at the time of last follow-up. Tumor size and lymph node status were significant predictors of poor 5-year OS $(P=0.037$ and $P=0.019$, respectively). Luminal B-like $(P=0.122)$, PR negative $(P=0.128)$ and poorly differentiated $(P=0.094)$ tumors tended to be associated with worse 5-year OS compared to luminal A-like, PR-positive and welldifferentiated tumors, respectively. Luminal B-like MBCs were associated with high grade $(P=0.00004)$, high MAI $(P=0.018)$ and $P R$ negativity $(P<0.00001)$ when compared to luminal A-like MBCs. 
The majority of BRCA2 germline mutation carriers presented with poorly differentiated tumors $(4 / 5$ were high grade; $P=0.149$ ) at a similar age as non-BRCA2mutation carriers (median 71 (range 44-78) vs 69 (range 32-87) years, respectively). KS patients tended to be younger ( 3 of 5 were aged $\leq 60 ; P=0.120$ ), with generally well-differentiated $(5 / 5 ; P=0.158)$, PR-positive tumors $(5 / 5 ; P=0.166)$.

\section{Somatic mutations}

Somatic mutations are listed in Supplementary Table 4. Overlapping FBC mutation-driver genes from four studies (Curtis et al. 2012, Nik-Zainal et al. 2016, Pereira et al. 2016, Bailey et al. 2018, Berger et al. 2018) were specifically compared to MBC. Of the 89 overlapping genes, 21 were not targeted and 1 (HRAS) was insufficiently covered by our panel, resulting in 67 interrogated genes. The remaining genes were mutated in $0-36 \%$ of MBC. Table 2 compares somatic mutation frequencies with FBC and MBC (Piscuoglio et al. 2016). Somatic mutations in TP53 were rare in MBC (3\%). In fact we detected only four (two in matched normal, four in the entire cohort) somatic mutations in TP53, two of them known from FBC and being likely oncogenic (OncoKB; Chakravarty et al. 2017), the other two unknown. None of the hotspots from FBC (R175, R248 and R273) were affected.

PIK3CA (36\%), KMT2C (21\%), PBRM1 (20\%) and GATA3 (15\%) were identified as most frequently mutated genes in this study (Fig. 1). The pattern of somatic mutations found in PIK3CA resembled that of FBC: all mutations found in $\mathrm{MBC}$ were missense mutations and $75-80 \%(12 / 15$ in matched normal; 30/40 in the entire cohort) affected the FBC hotspots (H1047, E542 and E545; Supplementary Fig. 1). Besides PIK3CA, other recurrent mutations in MBC included a K358 frameshift GATA3 mutation (4/25 GATA3 mutations), the E17K AKT1 mutation (3/8 AKT1 mutations) and the Q26K NCOR1 mutation (4/21 NCOR1 mutations).

PIK3CA mutations were significantly more abundant in poorly differentiated $(P=0.013 ; n=96)$ tumors with high mitotic activity $(P=0.014 ; n=99)$ and in lymph node-positive $(P=0.006 ; n=94)$ and younger patients $(P=0.046 ; n=108)$. Somatic mutations in PIK3CA were associated with worse 5-year OS $(P=0.026 ; n=90$; Supplementary Fig. 2). In multivariable analysis, however, PIK3CA somatic mutations did not independently predict survival alongside tumor grade $(P=0.034$; HR 2.627$)$ and size $(P=0.001$; HR 1.410).
ATM somatic mutations were associated with high tumor grade $(P=0.040 ; n=74)$ and high mitotic counts $(P=0.014 ; n=77)$. NOTCH2 mutations were more frequent in poorly differentiated tumors $(P=0.017 ; n=100)$ without lymph node metastases $(P=0.020 ; n=100)$. ATRX and $C R E B B P$ somatic mutations were more frequently observed in KS patients $(P=0.001(n=72)$ and $P=0.030(n=103)$, respectively). PTPRD mutations were more abundant in Ki67-high tumors $(P=0.005 ; n=96)$ and MED12 mutations in luminal A-like tumors $(P=0.026 ; n=86)$.

Compared to mutation frequencies in ER-positive FBC from METABRIC and TCGA, TP53 (both $P<0.0001$ ), MAP3K1 $(P=0.02$ and $P=0.05$, respectively) and $C D H 1$ ( $P=0.007$ and $P=0.0002$, respectively) somatic mutations were significantly less frequent in MBC (Table 2), whereas particularly PBRM1 (both $P<0.0001), N S D 1 \quad(P<0.0001$ TCGA) and SETD2 (both $P<0.0001$ ) mutations were more frequent. Overall, genes regulating chromatin function appeared more often affected in MBC (Fig. 2).

Mutational signature analysis revealed that 24\% of MBCs have a dominant signature 3 associated with defective homologous recombination DNA repair, whereas only $13 \%$ of TCGA FBCs demonstrated a dominant signature 3 (Fig. 3). In addition, another 24\% of MBCs have a dominant signature 8 , as compared to $0.4 \%$ of FBCs. In a recent review by Nik-Zainal et al., this signature 8 was reported to be increased in homologous recombination deficiency and late in cancer evolution (Nik-Zainal \& Morganella 2017).

\section{Copy number aberrations}

\section{CNA load}

On average, each tumor harbored 138 gene CNAs (range 6-1230), including amplifications $(Z>2.80)$ and homozygous deletions $(Z<-2.80)$. We observed no correlation between CNA load and ER/PR status, tumor histology, lymph node status, Ki67 status or age (data not shown). CNA load was not associated with mutational load $(P=0.286)$ or 5 -year survival $(P=0.549)$ and was similar between luminal A-like and luminal B-like tumors $(P=0.285)$. CNA load was however higher in poorly differentiated $(P=0.012)$ and larger tumors $(P=0.045)$ with high MAI $(P=0.011)$ (Supplementary Fig. 4). CNA load was significantly higher in tumors harboring mutations in KDM6A $(P=0.006)$ and NOTCH2 $(P=0.028)$.

Figure 4 depicts a heatmap of all CNAs in the MBC cohort after unsupervised hierarchical cluster analysis. MBCs of the same surrogate intrinsic molecular subtype did not cluster on the basis of their CNA profile, 


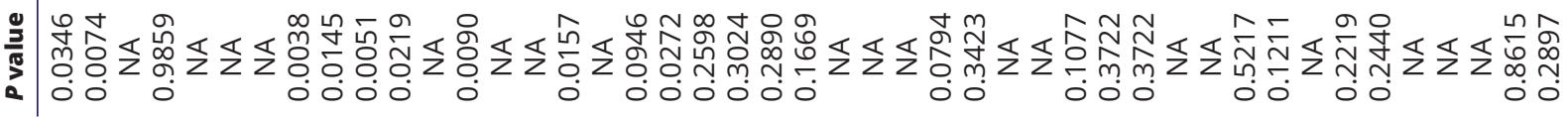

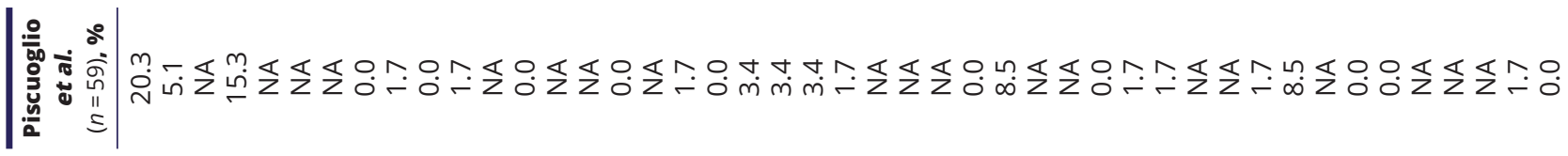

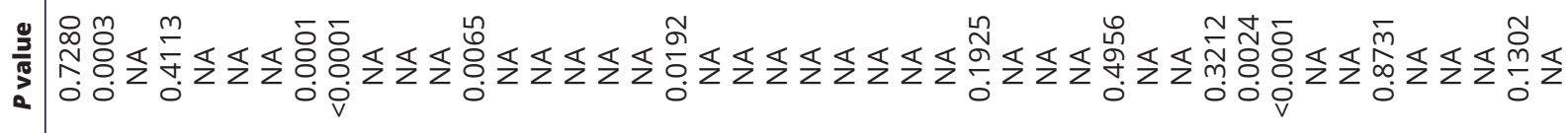

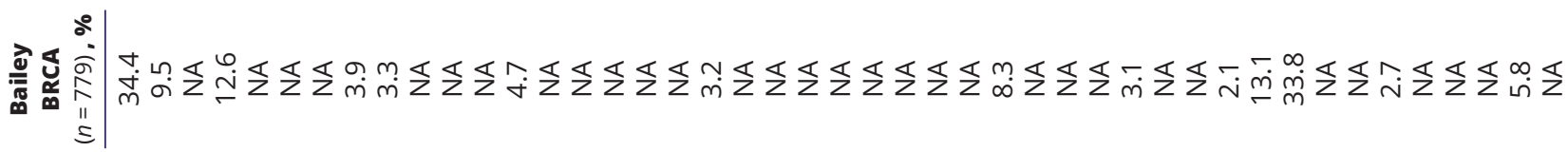

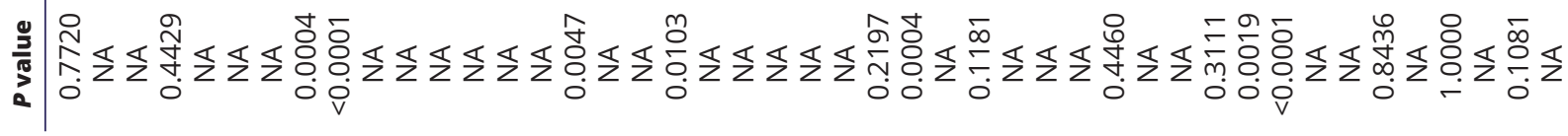

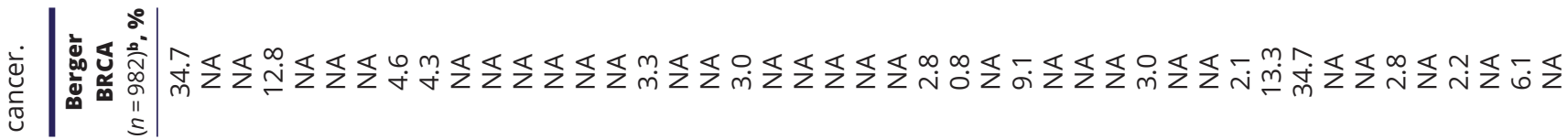

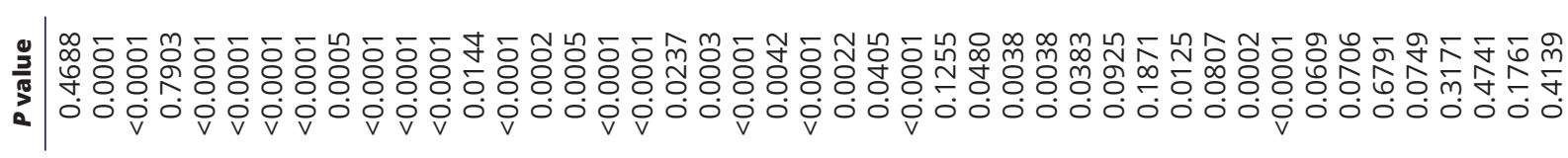

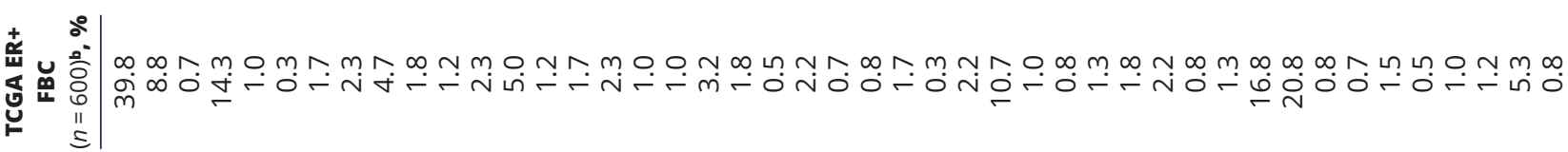

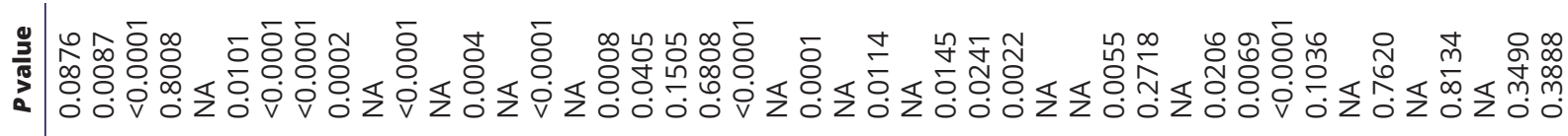

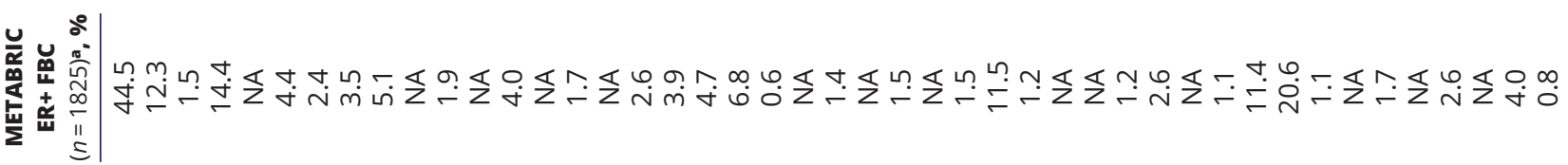

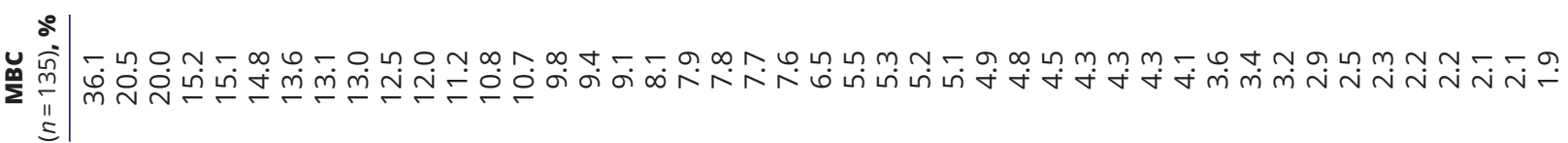

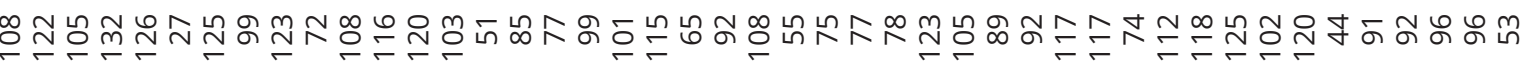
$\mid$ | 


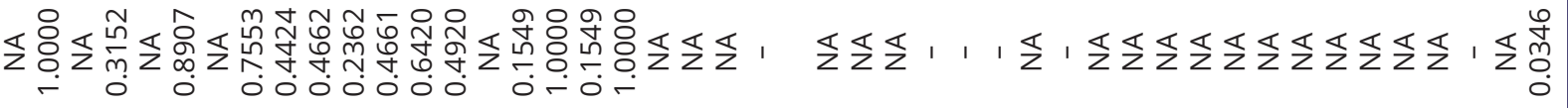

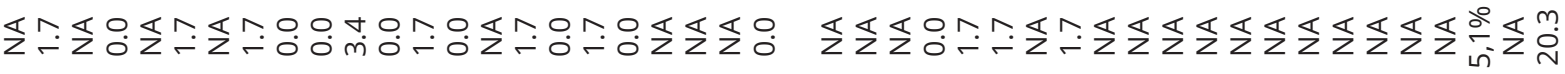

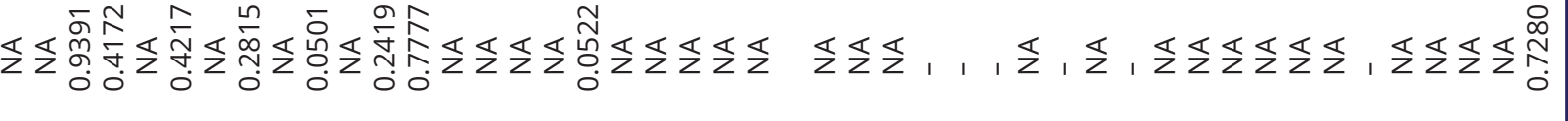

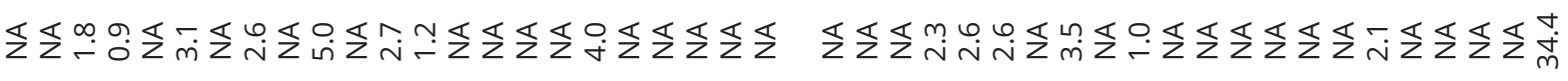

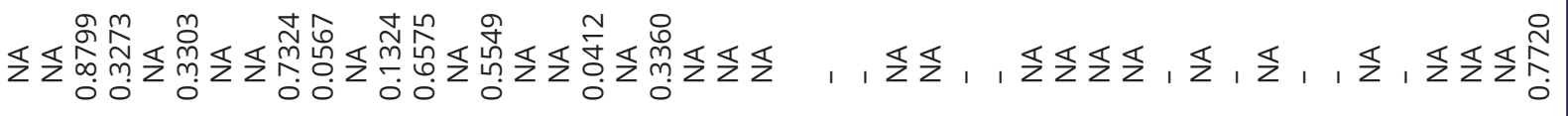

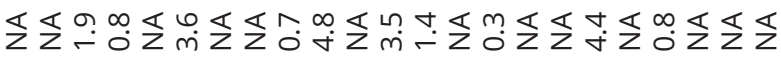

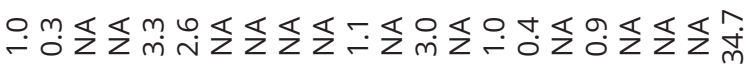

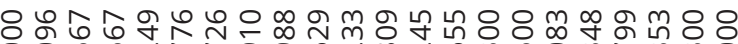

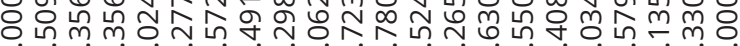

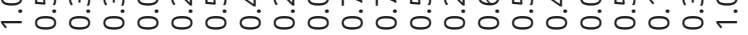

둥

$m m \infty m, \hat{m} \infty$ o

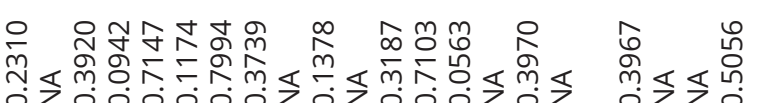

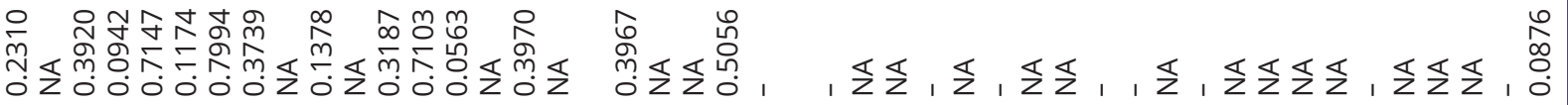

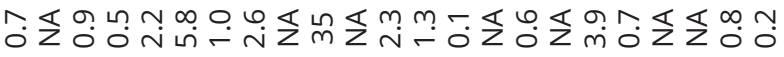

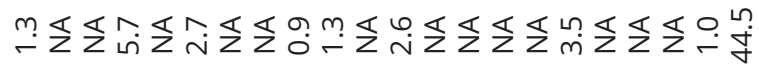

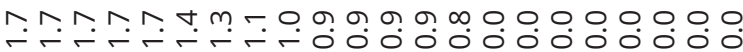

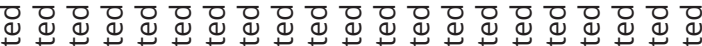

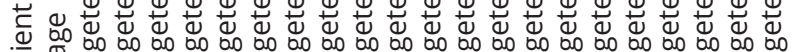

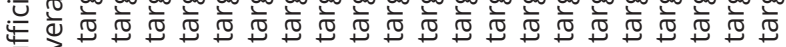

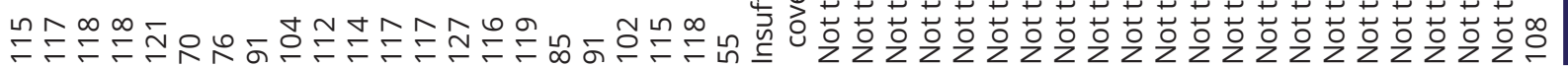

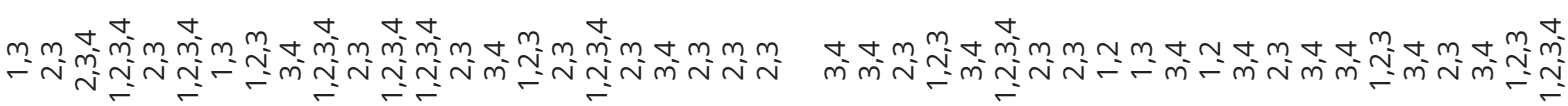

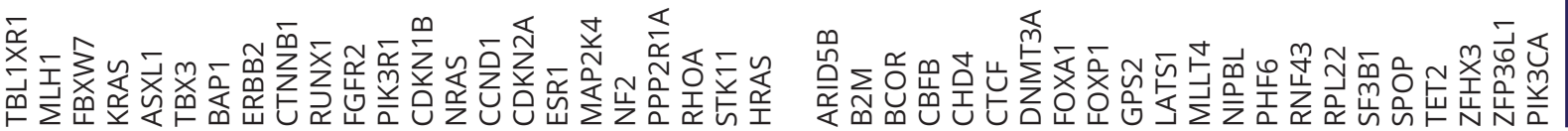

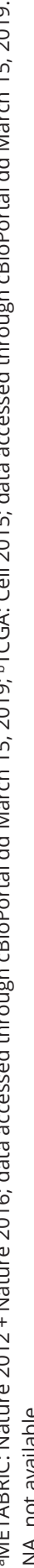




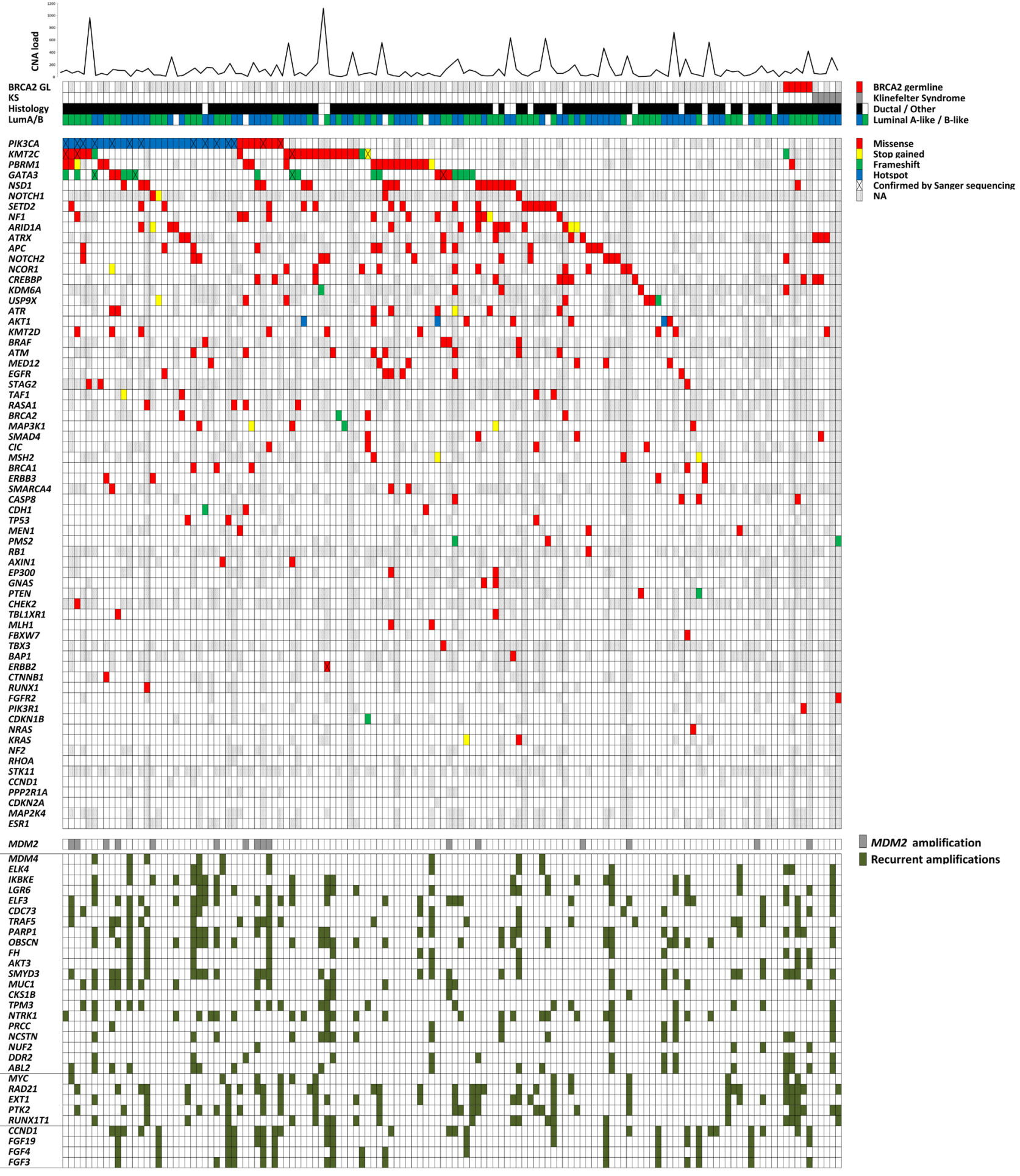

Figure 1

Somatic non-synonymous mutations and recurrent amplifications in 135 male breast cancers. Individual genes are represented as rows, and individual patients are represented as columns. Patients with pathogenic germline BRCA2 mutations or Klinefelter syndrome are indicated, as well as tumor histology and the distribution of surrogate IHC subtype. 


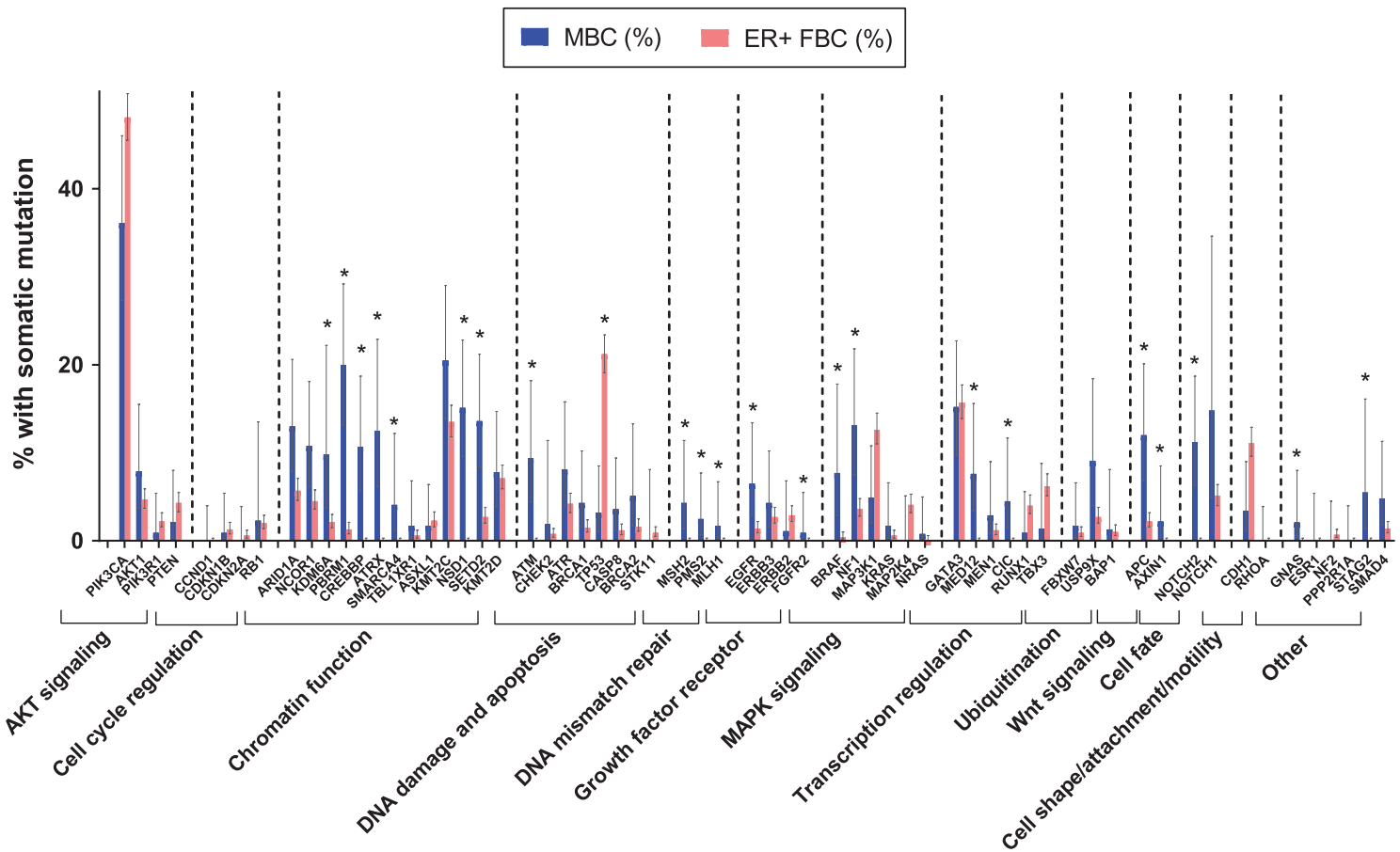

\section{Figure 2}

Comparison of MBC somatic mutation frequencies to METABRIC and TCGA ER-positive FBC. Genes have been sorted per function and 95\% CI (http:// vassarstats.net/prop1.html) have been indicated. * indicates a significant difference with METABRIC and/or TCGA.

whereas KS patients seemed to be subgrouped as a result of their CNA-naïve profile with chromosome X gains. In addition, a cluster of 17 mainly luminal A-like MBCs with high genomic instability was apparent. No correlation was observed with clinicopathological variables or survival when compared to the other MBCs but somatic mutation load tended to be slightly higher $(P=0.075)$.

\section{Amplifications}

Analysis of CNAs revealed that MBCs harbored recurrent amplifications on $8 \mathrm{p} / 8 \mathrm{q}, 16 \mathrm{p}, 20 \mathrm{q}$ and 1q. Supplementary Table 6 summarizes the associations of a set of 220 genes amplified in at least $10 \%$ of MBCs with intrinsic subtype, clinicopathological characteristics, SNV load and PIK3CA mutation status. Some of the most recurrently amplified genes in both cohorts (FF and FFPE) included UBR5 (24\%; 8q), TSC2 (22\%; 16p), ANK1 (22\%; 8p), OBSCN (21\%; 1q) and WHSC1L1 (21\%; 8p). A comparison between amplification frequencies in $\mathrm{MBC}$ and $\mathrm{smFBC}$ is presented in the same table. Merely 86/220 (39\%) frequently amplified genes in $\mathrm{MBC}$ were also amplified in more than $10 \%$ of ER-positive FBC. PANTHER reactome pathway analysis of these 220 genes demonstrated an overrepresentation of genes involved in extracellular matrix organization (three-fold enrichment; $P=0.0004$ ), chromatin organization (two-fold enrichment; $P=0.0012$ ) and STAT3 signaling (six-fold enrichment; $P=0.046$ ), whereas cell cycle-related genes were relatively underrepresented (0.4-fold enrichment; $P=0.0012$ ) (Mi et al. 2013). Based on The Drug Gene Interaction Database, $19 \%$ of these genes $(41 / 220)$ are clinically actionable and for $26 \%$ (57/220), drug interactions have been described (Supplementary Table 6).

Individually, 7/220 genes were indicative of poor 5-year OS when amplified: MDM2, PAK1, SCYL3, TGFB2, CLTC, SMYD3 and ASH1L (Supplementary Table 6). In multivariable analysis including clinical and pathological characteristics, the amplification status of PAK1, SCYL3, MDM2, ASH1L, E2F7, CLTC or TGFB2 remained in the model. In multivariable analysis including all seven genes, PAK1 (HR 3.65; $P=0.011$ ), TGFB2 (HR 3.14; $P=0.011$ ) and E2F7 (HR 2.98; $P=0.017$ ) remained. When all seven gene amplifications as well as PIK3CA mutations were included, only ASH1L (HR 2.44; $P=0.057$ ) and lymph node status (HR 2.44; $P=0.087$ ) remained in the model as independent predictors of survival (Supplementary Table 7).

Of particular interest was MDM2, amplified in as much as $13 \%$ of the cohort, and predictor of worse 5 -year OS ( $P=0.007$; Fig. 5$)$ even after correction for other established prognostic variables $(P=0.024$; Supplementary Table 7). MDM2 amplifications were more frequent in PR 


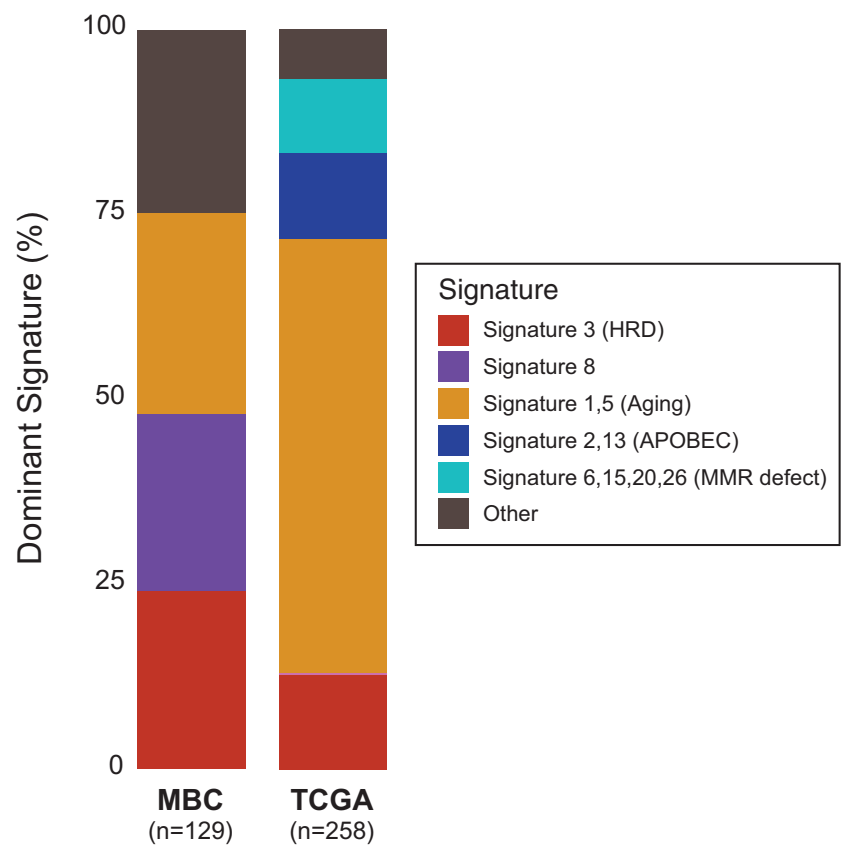

Figure 3

Mutational signature analysis in MBCs compared to ER/HER2- matched FBCs (TCGA). HRD, homologous recombination defect; MMR, mismatch repair

negative $(P=0.004)$ and poorly differentiated $(P=0.040)$ tumors (Supplementary Fig. 5). Co-amplifications with COL1A1 $(P=0.007)$, HER2 $(P=0.009), D N A H 11(P=0.027)$, PIK3C2B $(P=0.027)$ and PPM1D $(P=0.043)$ were frequent. Tumors harboring PIK3CA mutations $(P=0.005)$ or NF1 mutations $(P=0.026)$ were more likely to harbor MDM2 amplifications (Fig. 1 and Supplementary Fig. 5). MDM2 amplifications were significantly correlated with MDM2 protein overexpression $(P=0.001)$, but protein overexpression did not predict poor outcome $(P=0.337)$.

\section{Germline mutations}

With on average 1723 reads per normal tissue sample, we detected pathogenic BRCA2 germline mutations in 5/44 (11\%) matched normal samples using the IonTorrent Oncomine BRCA FFPE gene panel (library preparation failed for one sample; Supplementary Table 5). There was no indication for loss of heterozygosity of the WT BRCA2 allele based on variant allele frequencies. No pathogenic BRCA1 germline mutations were identified. Tumors from BRCA2 germline mutation carriers harbored a similar amount of somatic mutations and total CNAs compared to other MBCs. BRCA2-related tumors appear to have increased CNA counts on chromosome $8 \mathrm{q} \quad(P=0.056)$ accompanied by decreased counts on $8 \mathrm{p} \quad(P=0.004)$. All five BRCA2-carriers demonstrated UBR5 (8q; $P=0.002)$,
ASAP1 (8q; $P=0.001), C S M D 3$ (8q; $P=0.001)$ and CCNE2 (8q; $P=0.0002)$ amplification, but DNAH11 (7p; $P=0.003)$, RRM2B (8q; $P=0.007)$, FZD6 (8q; $P=0.010)$, RUNX1T1 (8q; $P=0.023)$ and $S G K 3$ (8q; $P=0.023)$ amplifications were also more frequently seen. We observed no enrichment for particular somatic mutations. None of the BRCA2 germline mutation carriers harbored a PIK3CA or GATA3 mutation (Fig. 1). Within AR, CHEK2 and PALB2 (FANCM was not targeted), we found no likely pathogenic germline mutations. Germline mutations in these genes predicted to have medium or high impact are described in the Supplementary results section.

\section{Discussion}

Compared to FBC, MBC has been relatively poorly characterized on the molecular level. Here, we have characterized a cohort of $135 \mathrm{MBC}, 46 \%$ of which were deemed luminal B-like tumors. This is consistent with a recent pathology review of the EORTC 10085/TBCRC/ BIG/NABCG International Male Breast Cancer Program where $49.3 \%$ of $1328 \mathrm{MBC}$ were luminal B-like tumors (Doebar et al. 2017). In our MBC series, 46\% of patients received radiotherapy, $16 \%$ chemotherapy and $42 \%$ endocrine therapy. Compared to the EORTC cohort, fewer men received chemotherapy (EORTC 27.7\%; 220/794 patients with available data) and endocrine therapy (EORTC 82.6\%; 583/706 patients with available data). These discrepancies are likely mainly due to uncertainties in treatment decision making. Studies investigating MBCs at the molecular level and correlating their findings with survival are therefore of the utmost importance.

TP53, CDH1, MAP3K1 and to a lesser extent PIK3CA, TBX3, MAP2K4, RUNX1 and PTEN somatic mutations appear to be less frequent in MBC compared to smFBC, whereas PBRM1, NSD1 and SETD2 somatic mutations seem to be more frequent.

After correction for multiple comparisons, there were no significant differences between our study and the MBC study of Piscuoglio et al. Similar to their MBC study, somatic mutations in TP53 were very rare (Piscuoglio et al. 2016). Their TP53 mutation frequency was however higher $(8.5 \%)$ than ours (3\%), possibly due to a different cohort composition. In FBC, luminal B-like tumors show a higher TP53 mutation frequency than luminal A-like tumors and the $\mathrm{MBC}$ set of Piscuoglio et al. was likely enriched for luminal B-like cancers (71\% of their cohort) (Cancer Genome Atlas Network 2012, Piscuoglio et al. 2016). In addition, a study using
C) 2019 Society for Endocrinology Published by Bioscientifica Ltd. Printed in Great Britain 


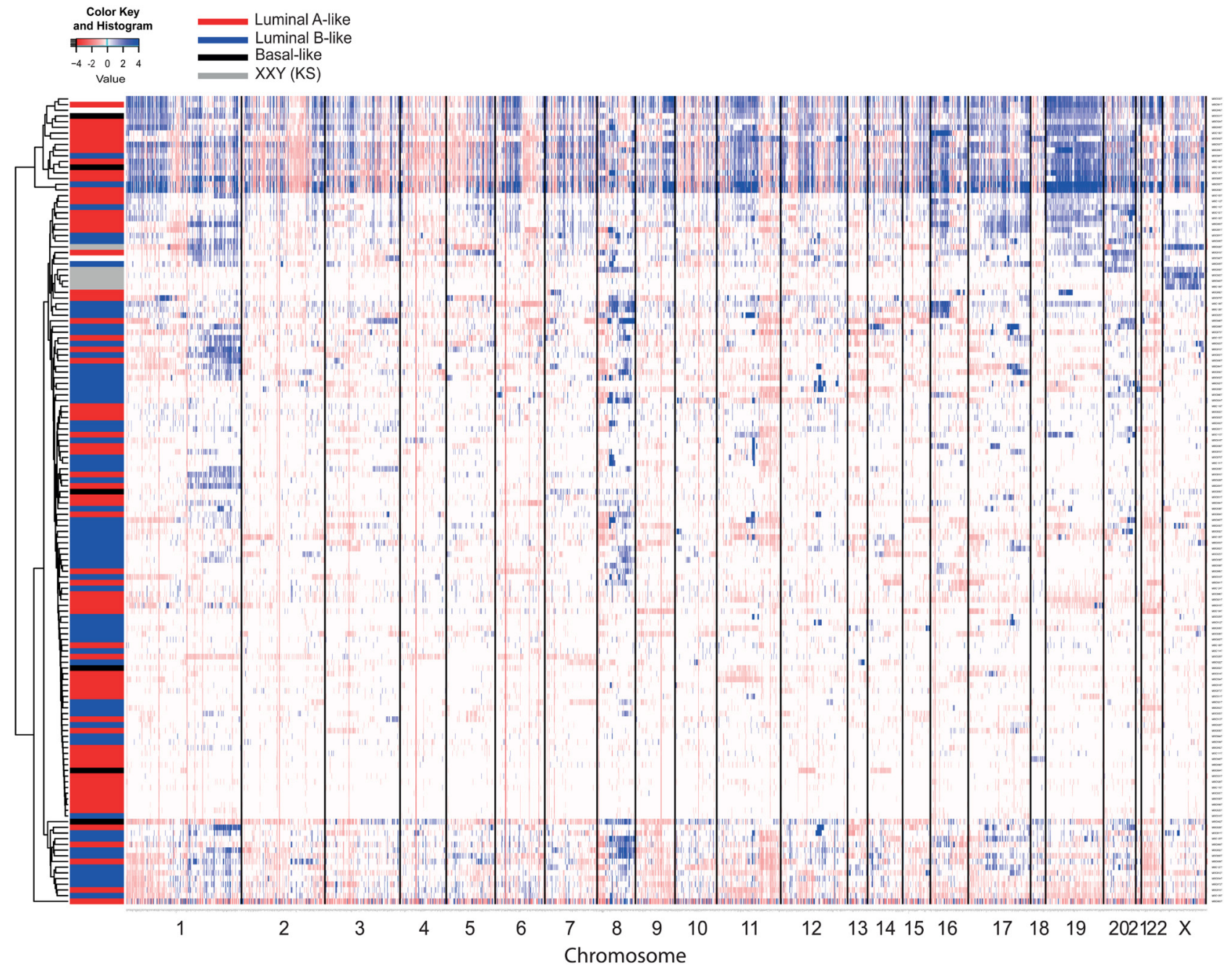

Figure 4

Heatmap of copy number alterations in the male breast cancers following unsupervised hierarchical cluster analysis. Two clusters seem to stand out: the top cluster with many events dominated by luminal A-like tumors and the bottom cluster dominated by luminal B-like cancers. Klinefelter syndrome patients (gray) show few copy number alterations.

a highly similar predecessor 'Cancer mini-genome' gene panel and approach in triple-negative FBC identified TP53 mutations in $55 \%$ of the specimens, thereby excluding technical bias (Lips et al. 2015). In contrast to TP53, the pattern of somatic mutations found in PIK3CA resembled that of FBC. Its somatic mutation frequency in our MBC cohort (36\%) was in between that reported by Piscuoglio et al. (MBC; $20 \%)$ and ER-positive FBC $(n=1431 ; 48 \%)$. PIK3CA mutations were associated with more aggressive tumor characteristics and reduced survival, in line with findings in ER-positive FBC subgroups (Pereira et al. 2016, Ishida et al. 2018).

Aside from PIK3CA, the serine/threonine protein kinase $A K T 1$ was the only other mutated gene with hotspots corresponding to FBC. The majority of $A K T 1$ missense mutations were E17K (4/9) or L52R (2/9) substitutions. Both mutations are known to be oncogenic and there is promising clinical data in FBC patients with AKT1 E17K mutant ER+ ductal breast cancer treated with the pan-AKT targeted inhibitor AZD5363 (level 3A evidence; oncoKB) (Davies et al. 2012, 2015, Addie et al. 2013, Hyman et al. 2017).

As expected from $\mathrm{FBC}$, most GATA3 mutations were likely oncogenic frameshift mutations including K358fs, H435fs, A332fs, R330fs and M294K/R (Cerami et al. 2012, Ellis et al. 2012, Gao et al. 2013). In contrast to Piscuoglio et al., GATA3 somatic mutations were not exclusive to luminal B-like MBC tumors (Piscuoglio et al. 2016). Overall, genes regulating chromatin function appear more often mutated in $\mathrm{MBC}$, and mutational
C 2019 Society for Endocrinology Published by Bioscientifica Ltd. Printed in Great Britain 


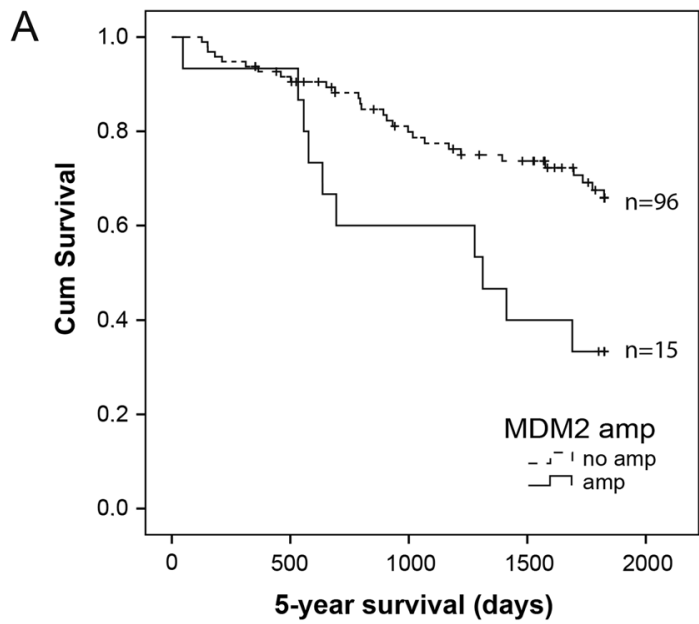

B MDM2 amp vs PR status
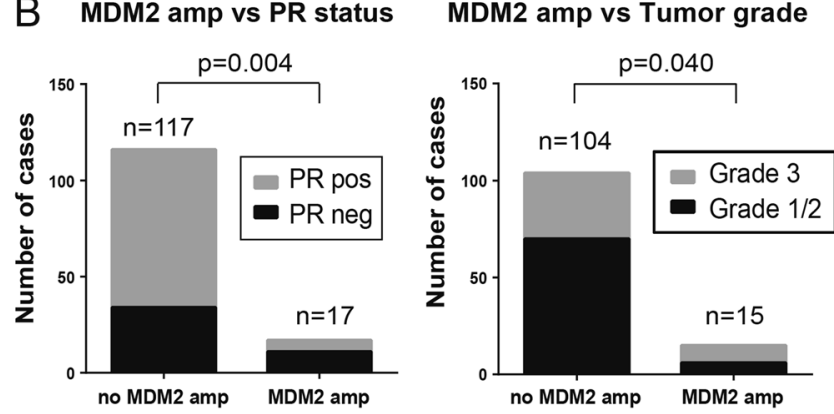

Figure 5

MDM2 amplification in male breast cancer is associated with poor 5-year overall survival, PR negativity and high tumor grade.

signatures 3 and 8 , both associated with homologous recombination deficiency, are more prevalent than in ER/ HER2-matched FBC. Of particular clinical importance, homologous recombination deficiency may point to a selective sensitivity to PARP (poly-ADP ribose polymerase) inhibitors (Nik-Zainal \& Morganella 2017).

Like $\mathrm{FBC}, \mathrm{MBC}$ is CNA driven, and despite many similarities in the CNA landscape between MBC and FBC (Curtis et al. 2012, Piscuoglio et al. 2016), only 40\% of frequently amplified genes in $\mathrm{MBC}$ were also frequently amplified in FBC, underlining differences in biology and genetics. MDM2 amplifications were observed in 13\% of the MBC cohort while in $\mathrm{FBC}$, these amplifications occur in merely $3.7 \%$ of cases. Since MDM2 mediates ubiquitination of p53, its increased amplification frequency may be related to the decreased TP53 mutation frequency observed in $\mathrm{MBC}$, the two events being mutually exclusive in the same pathway. Of note, besides MDM2, many of the aberrant genes in $\mathrm{MBC}$ seem to be involved in the inactivation of the p53 pathway (e.g. amplification of PAK1 and SMYD2, and inactivating mutations in ARID1A, PBRM1 and KMT2C) (Huang et al. 2006, Wu et al. 2014,
Woo et al. 2017). MDM2 amplifications predicted more aggressive tumor behavior and correlated with protein overexpression. The high rate of MDM2 overexpression in prostate and ER-positive FBC, and the ability of MDM2 inhibitors to ubiquitinate steroid hormone receptors, has led to the evaluation of this class of drugs in combination with endocrine therapies (CRUKE/12/032). Many MDM2 small-molecule inhibitors have only recently progressed from preclinical development into early clinical trials (such as RG7112, also known as RO5045337, and AMG232) (Burgess et al. 2016). Thus, MDM2 is a putative therapeutic target in MBC.

Four genes independently predicted poor OS in MBC when amplified: PAK1 (11q13.5-q14.1), ASH1L (1q22), E2F7 (12q21.2) and TGFB2 (1q41). PAK1 (p21 activated kinase 1) amplifications were present at a similar frequency compared to ER-positive FBC (12 vs 10\%) (Ong et al. 2011, Curtis et al. 2012, Ye \& Field 2012, Radu et al. 2014) and amplification and overexpression of PAK1 is associated with poor outcome in luminal FBC as well. In vitro testing of a small-molecule inhibitor, FRAX1036, in combination with docetaxel, further supported PAK1 as a potential target in breast cancer (Ong et al. 2015). PAK1 has also been implicated in tamoxifen resistance (Holm et al. 2006, Bostner et al. 2007, 2010), and in upregulating genes involved in the Fanconi anemia (FA)/BRCA pathway, paving the way for combined PAK1 and PARP inhibition in FA/BRCA-proficient cancers (Villamar Cruz et al. 2016). ASH1L, encoding a histone methyltransferase (HMT), showed a similar amplification frequency in MBC compared to ER-positive FBC (18 vs $21 \%$ ). This HMT is classified as dysregulated by genetic alterations and as candidate therapeutic target in FBC (Liu et al. 2015). ASH1L inhibitors are currently being developed (Rogawski et al. 2015). Atypical E2F transcription factor 7 (E2F7) amplification appears to be more frequent in MBC than ER-positive FBC (13 vs 1.4\%). E2F7 participates in various processes such as angiogenesis, polyploidization and DNA damage response. E2F7 overexpression leads to tamoxifen resistance in breast cancer cells (Chu et al. 2015) and anthracycline resistance in squamous cell carcinoma (Hazar-Rethinam et al. 2015). A small-molecule pan-E2F inhibitor (HLM006474) has been developed and was proven to be effective in a melanoma and lung cancer cell culture model (Ma et al. 2008, Kurtyka et al. 2014). TGFB2 encodes a secreted ligand of the transforming growth factor-beta superfamily and its mRNA levels predict tamoxifen response in breast cancer cells (Buck et al. 2008). Neutralizing antibodies to TGFB2 have been shown to reverse tamoxifen resistance of human 
breast carcinomas in vivo (Arteaga et al. 1999). Several pharmacological strategies have been developed to block TGF-beta signaling (Colak \& Ten Dijke 2017). Overall, $19 \%$ of the most frequently amplified genes in MBC are clinically actionable and for $26 \%$, drug interactions have been described, suggesting many potential druggable targets.

We detected pathogenic BRCA2 germline mutations in $11 \%$ of the paired tumor/normal subcohort $(5 / 44)$. Other larger studies have described similar frequencies (8-14\%) (Couch et al. 1996, Basham et al. 2002, Pritzlaff et al. 2017). In contrast to Silvestri et al. who reported a median age at diagnosis for male BRCA2 mutation carriers of 62 years and an inverse relationship between age at diagnosis and tumor grade in 375 male BRCA2 mutation carriers, our BRCA2 cohort consisted of older patients with poorly differentiated tumors (Silvestri et al. 2016). In our study, tumors from BRCA2 germline mutation carriers harbored a similar amount of somatic mutations and total CNAs compared to other MBCs, but appeared to have increased CNA counts on $8 \mathrm{q}$ and decreased counts on 8p. In light of the small BRCA2 mutation carrier cohort reported here, results based on this subgroup should however be interpreted with caution.

KS patients tended to be younger at presentation, with generally well-differentiated tumors with few CNAs. The increased risk of developing breast cancer for these KS patients can be attributed to a direct effect of the supernumerary $\mathrm{X}$ chromosome(s) or the combined action of abnormal chromosome dosage and hormonal imbalances (Kawakami et al. 2004, Bonomi et al. 2017).

It should be noted that this study used FFPE as well as fresh-frozen material. It is well recognized that the quality of FFPE samples due to fixation and tissue processing is inferior to that of frozen material. DNA extracted from FFPE tissues is fragmented which can lead to sequence artifacts (Do \& Dobrovic 2015). Sequence artifacts can be difficult to distinguish from true mutations, especially in the context of tumor heterogeneity and are an increasing interpretive problem in this era of massively parallel sequencing. We therefore included as much fresh-frozen material as possible. Nevertheless, in light of the rarity of MBC, we have included archived FFPE material as well. This might have led to an overestimation of mutational load (Yost et al. 2012).

In conclusion, this comprehensive molecular analysis of MBC suggests that, while MBCs show remarkable similarities to FBC, clear differences are also found, subscribing the amounting evidence that MBC should be seen as an entity of its own. This should also be reflected in the clinical approach that should refrain from merely imitating FBC management. As we have observed some genetic alterations to be clearly more prevalent in $\mathrm{MBC}$, for example MDM2 amplifications and homologous recombination-deficient mutational signatures, focus should be on associated relevant drugs. As such, honoring $\mathrm{MBC}$ for its specific molecular portrait may result in improvements in outcome that parallel those we have observed over the last years in FBC.

\section{Supplementary data}

This is linked to the online version of the paper at https://doi.org/10.1530/ ERC-19-0278

\section{Declaration of interest}

The authors declare that there is no conflict of interest that could be perceived as prejudicing the impartiality of the research reported.

\section{Funding}

This study was funded by the Dutch Cancer Society (UU 2012-5637), and in part by the National Institutes of Health/National Cancer Institute MSK Cancer Center Support Grant P30CA008748. J S R-F is funded in part by the Breast Cancer Research Foundation. The funding agencies had no role in the design of the study, the collection, analysis and interpretation of data and in writing the manuscript.

\section{Ethics approval and consent to participate}

The Dutch national ethical guidelines (www.federa.org) state that no ethical approval is required for the use of anonymous leftover tissue, and this is also part of the standard treatment agreement (Van Diest 2002).

\section{Availability of data and materials}

All sequencing data have been deposited in EGA under accession number EGAS00001002683. All data generated or analyzed during this study are included in this published article and its Supplementary information files.

\section{Acknowledgements}

The authors are grateful to the Borstkanker Onderzoek Groep (BOOG; study nr 2009-04; NCT01101425) for providing us with clinical and biological data of MBC patients.

\section{References}

Abdelwahab Yousef AJ 2017 Male breast cancer: epidemiology and risk factors. Seminars in Oncology 44 267-272. (https://doi.org/10.1053/j. seminoncol.2017.11.002)

Addie M, Ballard P, Buttar D, Crafter C, Currie G, Davies BR, Debreczeni J, Dry H, Dudley P, Greenwood R, et al. 2013 Discovery of 4-amino-N-[(1S)-1-(4-chlorophenyl)-3-hydroxypropyl]-1-(7Hpyrrolo[2,3-d]pyrimidin-4-yl)piperidine-4-carboxamide (AZD5363), (c) 2019 Society for Endocrinology Published by Bioscientifica Ltd. Printed in Great Britain 
an orally bioavailable, potent inhibitor of Akt kinases. Journal of Medicinal Chemistry 56 2059-2073. (https://doi.org/10.1021/ jm301762v)

Arteaga CL, Koli KM, Dugger TC \& Clarke R 1999 Reversal of tamoxifen resistance of human breast carcinomas in vivo by neutralizing antibodies to transforming growth factor-beta. Journal of the National Cancer Institute 91 46-53. (https://doi.org/10.1093/jnci/91.1.46)

Bailey MH, Tokheim C, Porta-Pardo E, Sengupta S, Bertrand D, Weerasinghe A, Colaprico A, Wendl MC, Kim J, Reardon B, et al. 2018 Comprehensive characterization of cancer driver genes and mutations. Cell 174 1034-1035. (https://doi.org/10.1016/j. cell.2018.07.034)

Basham VM, Lipscombe JM, Ward JM, Gayther SA, Ponder BA, Easton DF \& Pharoah PD 2002 BRCA1 and BRCA2 mutations in a population-based study of male breast cancer. Breast Cancer Research 4 R2. (https://doi.org/10.1186/bcr419)

Berger AC, Korkut A, Kanchi RS, Hegde AM, Lenoir W, Liu W, Liu Y, Fan H, Shen H, Ravikumar V, et al. 2018 A comprehensive pancancer molecular study of gynecologic and breast cancers. Cancer Cell 33 690.e9-705.e9. (https://doi.org/10.1016/j.ccell.2018.03.014)

Biesma HD, Schouten PC, Lacle MM, Sanders J, Brugman W, Kerkhoven R, Mandjes I, Van Der Groep P, Van Diest PJ \& Linn SC 2015 Copy number profiling by array comparative genomic hybridization identifies frequently occurring BRCA2-like male breast cancer. Genes, Chromosomes and Cancer 54 734-744. (https://doi. org/10.1002/gcc.22284)

Bonomi M, Rochira V, Pasquali D, Balercia G, Jannini EA, Ferlin A \& Klinefelter ItaliaN Group (KING) 2017 Klinefelter syndrome (KS): genetics, clinical phenotype and hypogonadism. Journal of Endocrinological Investigation 40 123-134. (https://doi.org/10.1007/ s40618-016-0541-6)

Bostner J, Ahnstrom Waltersson M, Fornander T, Skoog L, Nordenskjold B \& Stal O 2007 Amplification of CCND1 and PAK1 as predictors of recurrence and tamoxifen resistance in postmenopausal breast cancer. Oncogene 26 6997-7005. (https://doi.org/10.1038/sj. onc.1210506)

Bostner J, Skoog L, Fornander T, Nordenskjold B \& Stal O 2010 Estrogen receptor-alpha phosphorylation at serine 305 , nuclear p21-activated kinase 1 expression, and response to tamoxifen in postmenopausal breast cancer. Clinical Cancer Research 16 1624-1633. (https://doi. org/10.1158/1078-0432.CCR-09-1733)

Buck MB, Coller JK, Murdter TE, Eichelbaum M \& Knabbe C 2008 TGFbeta 2 and TbetaRII are valid molecular biomarkers for the antiproliferative effects of tamoxifen and tamoxifen metabolites in breast cancer cells. Breast Cancer Research and Treatment 107 15-24. (https://doi.org/10.1007/s10549-007-9526-7)

Burgess A, Chia KM, Haupt S, Thomas D, Haupt Y \& Lim E 2016 Clinical overview of MDM2/X-targeted therapies. Frontiers in Oncology 6 7. (https://doi.org/10.3389/fonc.2016.00007)

Callari M, Cappelletti V, De Cecco L, Musella V, Miodini P, Veneroni S, Gariboldi M, Pierotti MA \& Daidone MG 2011 Gene expression analysis reveals a different transcriptomic landscape in female and male breast cancer. Breast Cancer Research and Treatment 127 601-610. (https://doi.org/10.1007/s10549-010-1015-8)

Cancer Genome Atlas Network 2012 Comprehensive molecular portraits of human breast tumours. Nature 490 61-70. (https://doi. org/10.1038/nature11412)

Cerami E, Gao J, Dogrusoz U, Gross BE, Sumer SO, Aksoy BA, Jacobsen A, Byrne CJ, Heuer ML, Larsson E, et al. 2012 The cBio cancer genomics portal: an open platform for exploring multidimensional cancer genomics data. Cancer Discovery 2 401-404. (https://doi.org/10.1158/2159-8290.CD-12-0095)

Chakravarty D, Gao J, Phillips SM, Kundra R, Zhang H, Wang J, Rudolph JE, Yaeger R, Soumerai T, Nissan MH, et al. 2017 OncoKB: a precision oncology knowledge base. JCO Precision Oncology 2017 [epub]. (https://doi.org/10.1200/PO.17.00011)
Chu J, Zhu Y, Liu Y, Sun L, Lv X, Wu Y, Hu P, Su F, Gong C, Song E, et al. 2015 E2F7 overexpression leads to tamoxifen resistance in breast cancer cells by competing with E2F1 at miR-15a/16 promoter. Oncotarget 6 31944-31957. (https://doi.org/10.18632/ oncotarget.5128)

Colak S \& Ten Dijke P 2017 Targeting TGF-beta signaling in cancer. Trends in Cancer 3 56-71. (https://doi.org/10.1016/j. trecan.2016.11.008)

Couch FJ, Farid LM, Deshano ML, Tavtigian SV, Calzone K, Campeau L, Peng Y, Bogden B, Chen Q, Neuhausen S, et al. 1996 BRCA2 germline mutations in male breast cancer cases and breast cancer families. Nature Genetics 13 123-125. (https://doi.org/10.1038/ ng0596-123)

Curtis C, Shah SP, Chin SF, Turashvili G, Rueda OM, Dunning MJ, Speed D, Lynch AG, Samarajiwa S, Yuan Y, et al. 2012 The genomic and transcriptomic architecture of 2,000 breast tumours reveals novel subgroups. Nature 486 346-352. (https://doi.org/10.1038/ nature10983)

Davies BR, Greenwood H, Dudley P, Crafter C, Yu DH, Zhang J, Li J, Gao B, Ji Q, Maynard J, et al. 2012 Preclinical pharmacology of AZD5363, an inhibitor of AKT: pharmacodynamics, antitumor activity, and correlation of monotherapy activity with genetic background. Molecular Cancer Therapeutics 11 873-887. (https://doi. org/10.1158/1535-7163.MCT-11-0824-T)

Davies BR, Guan N, Logie A, Crafter C, Hanson L, Jacobs V, James N, Dudley P, Jacques K, Ladd B, et al. 2015 Tumors with AKT1E17K mutations are rational targets for single agent or combination therapy with AKT inhibitors. Molecular Cancer Therapeutics 14 2441-2451. (https://doi.org/10.1158/1535-7163.MCT-15-0230)

Do H \& Dobrovic A 2015 Sequence artifacts in DNA from formalin-fixed tissues: causes and strategies for minimization. Clinical Chemistry $\mathbf{6 1}$ 64-71. (https://doi.org/10.1373/clinchem.2014.223040)

Doebar SC, Slaets L, Cardoso F, Giordano SH, Bartlett JM, Tryfonidis K, Dijkstra NH, Schroder CP, Van Asperen CJ, Linderholm B, et al. 2017 Male breast cancer precursor lesions: analysis of the EORTC 10085/ TBCRC/BIG/NABCG International Male Breast Cancer Program. Modern Pathology 30 509-518. (https://doi.org/10.1038/ modpathol.2016.229)

Ellis MJ, Ding L, Shen D, Luo J, Suman VJ, Wallis JW, Van Tine BA, Hoog J, Goiffon RJ, Goldstein TC, et al. 2012 Whole-genome analysis informs breast cancer response to aromatase inhibition. Nature $\mathbf{4 8 6}$ 353-360. (https://doi.org/10.1038/nature11143)

Elston CW \& Ellis IO 1991 Pathological prognostic factors in breast cancer. I. The value of histological grade in breast cancer: experience from a large study with long-term follow-up. Histopathology 19 403410. (https://doi.org/10.1111/j.1365-2559.1991.tb00229.x)

Fassan M, Baffa R, Palazzo JP, Lloyd J, Crosariol M, Liu CG, Volinia S, Alder H, Rugge M, Croce CM, et al. 2009 MicroRNA expression profiling of male breast cancer. Breast Cancer Research 11 R58. (https://doi.org/10.1186/bcr2348)

Gao J, Aksoy BA, Dogrusoz U, Dresdner G, Gross B, Sumer SO, Sun Y, Jacobsen A, Sinha R, Larsson E, et al. 2013 Integrative analysis of complex cancer genomics and clinical profiles using the cBioPortal. Science Signaling 6 pl1. (https://doi.org/10.1126/scisignal.2004088)

Gao Y, Jones A, Fasching PA, Ruebner M, Beckmann MW, Widschwendter M \& Teschendorff AE 2015 The integrative epigenomic-transcriptomic landscape of ER positive breast cancer. Clinical Epigenetics 7 126. (https://doi.org/10.1186/s13148-0150159-0)

Giordano SH 2018 Breast cancer in men. New England Journal of Medicine 378 2311-2320. (https://doi.org/10.1056/NEJMra1707939)

Giordano SH, Cohen DS, Buzdar AU, Perkins G \& Hortobagyi GN 2004 Breast carcinoma in men: a population-based study. Cancer $10151-$ 57. (https://doi.org/10.1002/cncr.20312)

Goldhirsch A, Winer EP, Coates AS, Gelber RD, Piccart-Gebhart M, Thurlimann B, Senn HJ \& Panel members 2013 Personalizing the https://erc bioscientifica.com

https://doi.org/10.1530/ERC-19-0278
C) 2019 Society for Endocrinology Published by Bioscientifica Ltd. Printed in Great Britain 
treatment of women with early breast cancer: highlights of the St Gallen International Expert Consensus on the Primary Therapy of Early Breast Cancer 2013. Annals of Oncology 24 2206-2223. (https:// doi.org/10.1093/annonc/mdt303)

Harakalova M, Mokry M, Hrdlickova B, Renkens I, Duran K, Van Roekel H, Lansu N, Van Roosmalen M, De Bruijn E, Nijman IJ, et al. 2011 Multiplexed array-based and in-solution genomic enrichment for flexible and cost-effective targeted next-generation sequencing. Nature Protocols 6 1870-1886. (https://doi.org/10.1038/ nprot.2011.396)

Hazar-Rethinam M, De Long LM, Gannon OM, Topkas E, Boros S, Vargas AC, Dzienis M, Mukhopadhyay P, Simpson F, Endo-Munoz L, et al. 2015 A novel E2F/sphingosine kinase 1 axis regulates anthracycline response in squamous cell carcinoma. Clinical Cancer Research 21 417-427. (https://doi.org/10.1158/1078-0432.CCR-141962)

Holm C, Rayala S, Jirstrom K, Stal O, Kumar R \& Landberg G 2006 Association between Pak1 expression and subcellular localization and tamoxifen resistance in breast cancer patients. Journal of the National Cancer Institute 98 671-680. (https://doi.org/10.1093/jnci/ djj185)

Hoogstraat M, Hinrichs JW, Besselink NJ, Radersma-Van Loon JH, De Voijs CM, Peeters T, Nijman IJ, De Weger RA, Voest EE, Willems SM, et al. 2015 Simultaneous detection of clinically relevant mutations and amplifications for routine cancer pathology. Journal of Molecular Diagnostics 17 10-18. (https://doi.org/10.1016/j.jmoldx.2014.09.004)

Huang J, Perez-Burgos L, Placek BJ, Sengupta R, Richter M, Dorsey JA, Kubicek S, Opravil S, Jenuwein T \& Berger SL 2006 Repression of p53 activity by Smyd2-mediated methylation. Nature $\mathbf{4 4 4}$ 629-632. (https://doi.org/10.1038/nature05287)

Hyman DM, Smyth LM, Donoghue MTA, Westin SN, Bedard PL, Dean EJ, Bando H, El-Khoueiry AB, Perez-Fidalgo JA, Mita A, et al. 2017 AKT inhibition in solid tumors with AKT1 mutations. Journal of Clinical Oncology 35 2251-2259. (https://doi.org/10.1200/ JCO.2017.73.0143)

Ishida N, Baba M, Hatanaka Y, Hagio K, Okada H, Hatanaka KC, Togashi K, Matsuno Y \& Yamashita H 2018 PIK3CA mutation, reduced AKT serine 473 phosphorylation, and increased ERalpha serine 167 phosphorylation are positive prognostic indicators in postmenopausal estrogen receptor-positive early breast cancer. Oncotarget 9 17711-17724. (https://doi.org/10.18632/ oncotarget.24845)

Jemal A, Siegel R, Xu J \& Ward E 2010 Cancer statistics, 2010. CA: A Cancer Journal for Clinicians 60 277-300. (https://doi.org/10.3322/ caac.20073)

Johansson I, Nilsson C, Berglund P, Strand C, Jonsson G, Staaf J, Ringner M, Nevanlinna H, Barkardottir RB, Borg A, et al. 2011 Highresolution genomic profiling of male breast cancer reveals differences hidden behind the similarities with female breast cancer. Breast Cancer Research and Treatment 129 747-760. (https://doi.org/10.1007/ s10549-010-1262-8)

Johansson I, Nilsson C, Berglund P, Lauss M, Ringner M, Olsson H, Luts L, Sim E, Thorstensson S, Fjallskog ML, et al. 2012 Gene expression profiling of primary male breast cancers reveals two unique subgroups and identifies N-acetyltransferase-1 (NAT1) as a novel prognostic biomarker. Breast Cancer Research 14 R31. (https:// doi.org/10.1186/bcr3116)

Johansson I, Lauss M, Holm K, Staaf J, Nilsson C, Fjallskog ML, Ringner M \& Hedenfalk I 2015 Genome methylation patterns in male breast cancer - identification of an epitype with hypermethylation of polycomb target genes. Molecular Oncology 9 1565-1579. (https://doi.org/10.1016/j.molonc.2015.04.013)

Kawakami T, Zhang C, Taniguchi T, Kim CJ, Okada Y, Sugihara H, Hattori T, Reeve AE, Ogawa O \& Okamoto K 2004 Characterization of loss-of-inactive $\mathrm{X}$ in Klinefelter syndrome and female-derived cancer cells. Oncogene 23 6163-6169. (https://doi.org/10.1038/sj. onc.1207808)

Kornegoor R, Moelans CB, Verschuur-Maes AH, Hogenes MCh, De Bruin PC, Oudejans JJ \& Van Diest PJ 2012a Promoter hypermethylation in male breast cancer: analysis by multiplex ligation-dependent probe amplification. Breast Cancer Research 14 R101. (https://doi.org/10.1186/bcr3220)

Kornegoor R, Moelans CB, Verschuur-Maes AH, Hogenes MC, De Bruin PC, Oudejans JJ, Marchionni L \& Van Diest PJ 2012b Oncogene amplification in male breast cancer: analysis by multiplex ligation-dependent probe amplification. Breast Cancer Research and Treatment 135 49-58. (https://doi.org/10.1007/s10549-012-2051-3)

Kornegoor R, Verschuur-Maes AH, Buerger H, Hogenes MC, De Bruin PC, Oudejans JJ, Van Der Groep P, Hinrichs B \& Van Diest PJ 2012c Molecular subtyping of male breast cancer by immunohistochemistry. Modern Pathology 25 398-404. (https://doi. org/10.1038/modpathol.2011.174)

Kurtyka CA, Chen L \& Cress WD 2014 E2F inhibition synergizes with paclitaxel in lung cancer cell lines. PLOS ONE 9 e96357. (https://doi. org/10.1371/journal.pone.0096357)

Lacle MM, Kornegoor R, Moelans CB, Maes-Verschuur AH, Van Der Pol C, Witkamp AJ, Van Der Wall E, Rueschoff J, Buerger H \& Van Diest PJ 2013 Analysis of copy number changes on chromosome 16q in male breast cancer by multiplex ligation-dependent probe amplification. Modern Pathology 26 1461-1467. (https://doi. org/10.1038/modpathol.2013.94)

Lacle MM, Moelans CB, Kornegoor R, Van Der Pol C, Witkamp AJ, Van Der Wall E, Rueschoff J, Buerger H \& Van Diest PJ 2015 Chromosome 17 copy number changes in male breast cancer. Cellular Oncology 38 237-245. (https://doi.org/10.1007/s13402-0150227-7)

Lehmann U, Streichert T, Otto B, Albat C, Hasemeier B, Christgen H, Schipper E, Hille U, Kreipe HH \& Langer F 2010 Identification of differentially expressed microRNAs in human male breast cancer. BMC Cancer 10 109. (https://doi.org/10.1186/1471-2407-10-109)

Lips EH, Michaut M, Hoogstraat M, Mulder L, Besselink NJ, Koudijs MJ, Cuppen E, Voest EE, Bernards R, Nederlof PM, et al. 2015 Next generation sequencing of triple negative breast cancer to find predictors for chemotherapy response. Breast Cancer Research 17134. (https://doi.org/10.1186/s13058-015-0642-8)

Liu L, Kimball S, Liu H, Holowatyj A \& Yang ZQ 2015 Genetic alterations of histone lysine methyltransferases and their significance in breast cancer. Oncotarget 6 2466-2482. (https://doi.org/10.18632/ oncotarget.2967)

Ma Y, Kurtyka CA, Boyapalle S, Sung SS, Lawrence H, Guida W \& Cress WD 2008 A small-molecule E2F inhibitor blocks growth in a melanoma culture model. Cancer Research 68 6292-6299. (https:// doi.org/10.1158/0008-5472.CAN-08-0121)

Mckenna A, Hanna M, Banks E, Sivachenko A, Cibulskis K, Kernytsky A, Garimella K, Altshuler D, Gabriel S, Daly M, et al. 2010 The Genome Analysis Toolkit: a MapReduce framework for analyzing nextgeneration DNA sequencing data. Genome Research 20 1297-1303. (https://doi.org/10.1101/gr.107524.110)

Mi H, Muruganujan A, Casagrande JT \& Thomas PD 2013 Large-scale gene function analysis with the PANTHER classification system. Nature Protocols 8 1551-1566. (https://doi.org/10.1038/ nprot.2013.092)

Mi H, Huang X, Muruganujan A, Tang H, Mills C, Kang D \& Thomas PD 2017 PANTHER version 11: expanded annotation data from Gene Ontology and Reactome pathways, and data analysis tool enhancements. Nucleic Acids Research 45 D183-D189. (https://doi. org/10.1093/nar/gkw1138)

Mueller JJ, Schlappe BA, Kumar R, Olvera N, Dao F, Abu-Rustum N, Aghajanian C, Delair D, Hussein YR, Soslow RA, et al. 2018 Massively parallel sequencing analysis of mucinous ovarian (c) 2019 Society for Endocrinology Published by Bioscientifica Ltd. Printed in Great Britain 
carcinomas: genomic profiling and differential diagnoses. Gynecologic Oncology 150 127-135. (https://doi.org/10.1016/j.ygyno.2018.05.008)

Nik-Zainal S \& Morganella S 2017 Mutational signatures in breast cancer: the problem at the DNA level. Clinical Cancer Research 23 2617-2629. (https://doi.org/10.1158/1078-0432.CCR-16-2810)

Nik-Zainal S, Davies H, Staaf J, Ramakrishna M, Glodzik D, Zou X, Martincorena I, Alexandrov LB, Martin S, Wedge DC, et al. 2016 Landscape of somatic mutations in 560 breast cancer whole-genome sequences. Nature 534 47-54. (https://doi.org/10.1038/nature17676)

Ong CC, Jubb AM, Haverty PM, Zhou W, Tran V, Truong T, Turley H, O'brien T, Vucic D, Harris AL, et al. 2011 Targeting p21-activated kinase 1 (PAK1) to induce apoptosis of tumor cells. PNAS 108 71777182. (https://doi.org/10.1073/pnas.1103350108)

Ong CC, Gierke S, Pitt C, Sagolla M, Cheng CK, Zhou W, Jubb AM, Strickland L, Schmidt M, Duron SG, et al. 2015 Small molecule inhibition of group I p21-activated kinases in breast cancer induces apoptosis and potentiates the activity of microtubule stabilizing agents. Breast Cancer Research 17 59. (https://doi.org/10.1186/s13058015-0564-5)

Pereira B, Chin SF, Rueda OM, Vollan HK, Provenzano E, Bardwell HA, Pugh M, Jones L, Russell R, Sammut SJ, et al. 2016 The somatic mutation profiles of 2,433 breast cancers refine their genomic and transcriptomic landscapes. Nature Communications 7 11479. (https:// doi.org/10.1038/ncomms11479)

Piscuoglio S, Ng CK, Murray MP, Guerini-Rocco E, Martelotto LG, Geyer FC, Bidard FC, Berman S, Fusco N, Sakr RA, et al. 2016 The genomic landscape of male breast cancers. Clinical Cancer Research 22 4045-4056. (https://doi.org/10.1158/1078-0432.CCR-15-2840)

Pritzlaff M, Summerour P, Mcfarland R, Li S, Reineke P, Dolinsky JS, Goldgar DE, Shimelis H, Couch FJ, Chao EC, et al. 2017 Male breast cancer in a multi-gene panel testing cohort: insights and unexpected results. Breast Cancer Research and Treatment 161 575-586. (https:// doi.org/10.1007/s10549-016-4085-4)

Radu M, Semenova G, Kosoff R \& Chernoff J 2014 PAK signalling during the development and progression of cancer. Nature Reviews: Cancer 14 13-25. (https://doi.org/10.1038/nrc3645)

Rizzolo P, Silvestri V, Valentini V, Zelli V, Zanna I, Masala G, Bianchi S, Palli D \& Ottini L 2018 Gene-specific methylation profiles in BRCAmutation positive and BRCA-mutation negative male breast cancers. Oncotarget 9 19783-19792. (https://doi.org/10.18632/ oncotarget.24856)

Rogawski DS, Ndoj J, Cho HJ, Maillard I, Grembecka J \& Cierpicki T 2015 Two loops undergoing concerted dynamics regulate the activity of the ASH1L histone methyltransferase. Biochemistry $\mathbf{5 4}$ 5401-5413. (https://doi.org/10.1021/acs.biochem.5b00697)

Rosenthal R, Mcgranahan N, Herrero J, Taylor BS \& Swanton C 2016 DeconstructSigs: delineating mutational processes in single tumors distinguishes DNA repair deficiencies and patterns of carcinoma evolution. Genome Biology 17 31. (https://doi.org/10.1186/s13059. 016-0893-4)

Silvestri V, Barrowdale D, Mulligan AM, Neuhausen SL, Fox S, Karlan BY, Mitchell G, James P, Thull DL, Zorn KK, et al. 2016 Male breast cancer in BRCA1 and BRCA2 mutation carriers: pathology data from the Consortium of Investigators of Modifiers of BRCA1/2. Breast Cancer Research 18 15. (https://doi.org/10.1186/s13058-016-0671-y)

Silvestri V, Zelli V, Valentini V, Rizzolo P, Navazio AS, Coppa A, Agata S, Oliani C, Barana D, Castrignano T, et al. 2017 Whole-exome sequencing and targeted gene sequencing provide insights into the role of PALB2 as a male breast cancer susceptibility gene. Cancer $\mathbf{1 2 3}$ 210-218. (https://doi.org/10.1002/cncr.30337)
Silvestri V, Rizzolo P, Zelli V, Valentini V, Zanna I, Bianchi S, Tibiletti MG, Varesco L, Russo A, Tommasi S, et al. 2018 A possible role of FANCM mutations in male breast cancer susceptibility: results from a multicenter study in Italy. Breast 38 92-97. (https://doi. org/10.1016/j.breast.2017.12.013)

Stang A \& Thomssen C 2008 Decline in breast cancer incidence in the United States: what about male breast cancer? Breast Cancer Research and Treatment 112 595-596. (https://doi.org/10.1007/s10549-0079882-3)

Thomas DB, Rosenblatt K, Jimenez LM, Mctiernan A, Stalsberg H, Stemhagen A, Thompson WD, Curnen MG, Satariano W \& Austin DF 1994 Ionizing radiation and breast cancer in men (United States). Cancer Causes and Control 5 9-14. (https://doi.org/10.1007/ BF01830721)

Tommasi S, Mangia A, Iannelli G, Chiarappa P, Rossi E, Ottini L, Mottolese M, Zoli W, Zuffardi O \& Paradiso A 2011 Gene copy number variation in male breast cancer by aCGH. Cellular Oncology 34 467-473. (https://doi.org/10.1007/s13402-011-0041-9)

Van Der Auwera GA, Carneiro MO, Hartl C, Poplin R, Del Angel G, Levy-Moonshine A, Jordan T, Shakir K, Roazen D, Thibault J, et al. 2013. From FastQ data to high confidence variant calls: the Genome Analysis Toolkit best practices pipeline. Current Protocols in Bioinformatics Intranet 43 11.10.1-33.

Van Diest PJ 2002 No consent should be needed for using leftover body material for scientific purposes. For. BMJ 325 648-651. (https://doi. org/10.1136/bmj.325.7365.648)

Van Diest PJ, Baak JP, Matze-Cok P, Wisse-Brekelmans EC, Van Galen CM, Kurver PH, Bellot SM, Fijnheer J, Van Gorp LH \& Kwee WS 1992 Reproducibility of mitosis counting in 2,469 breast cancer specimens: results from the Multicenter Morphometric Mammary Carcinoma Project. Human Pathology 23 603-607. (https:// doi.org/10.1016/0046-8177(92)90313-r)

Villamar Cruz O, Prudnikova TY, Araiza-Olivera D, Perez-Plasencia C, Johnson N, Bernhardy AJ, Slifker M, Renner C, Chernoff J \& AriasRomero LE 2016 Reduced PAK1 activity sensitizes FA/BRCAproficient breast cancer cells to PARP inhibition. Oncotarget 7 76590-76603. (https://doi.org/10.18632/oncotarget.12576)

Weiss JR, Moysich KB \& Swede H 2005 Epidemiology of male breast cancer. Cancer Epidemiology, Biomarkers and Prevention 14 20-26.

Wolff AC, Hammond ME, Hicks DG, Dowsett M, Mcshane LM, Allison KH, Allred DC, Bartlett JM, Bilous M, Fitzgibbons P, et al. 2013 Recommendations for human epidermal growth factor receptor 2 testing in breast cancer: American Society of Clinical Oncology/ College of American Pathologists clinical practice guideline update. Journal of Clinical Oncology 31 3997-4013. (https://doi.org/10.1200/ JCO.2013.50.9984)

Woo TG, Yoon MH, Hong SD, Choi J, Ha NC, Sun H \& Park BJ 2017 Anti-cancer effect of novel PAK1 inhibitor via induction of PUMAmediated cell death and p21-mediated cell cycle arrest. Oncotarget 8 23690-23701. (https://doi.org/10.18632/oncotarget.15783)

Wu RC, Wang TL \& Shih IeM 2014 The emerging roles of ARID1A in tumor suppression. Cancer Biology and Therapy 15 655-664. (https:// doi.org/10.4161/cbt.28411)

Ye DZ \& Field J 2012 PAK signaling in cancer. Cellular Logistics 2 105116. (https://doi.org/10.4161/cl.21882)

Yost SE, Smith EN, Schwab RB, Bao L, Jung H, Wang X, Voest E, Pierce JP, Messer K, Parker BA, et al. 2012 Identification of highconfidence somatic mutations in whole genome sequence of formalin-fixed breast cancer specimens. Nucleic Acids Research 40 e107. (https://doi.org/10.1093/nar/gks299)

Received in final form 27 June 2019

Accepted 23 July 2019

Accepted Preprint published online 23 July 2019 https://erc.bioscientifica.com https://doi.org/10.1530/ERC-19-0278 (c) 2019 Society for Endocrinology Published by Bioscientifica Ltd. Printed in Great Britain 